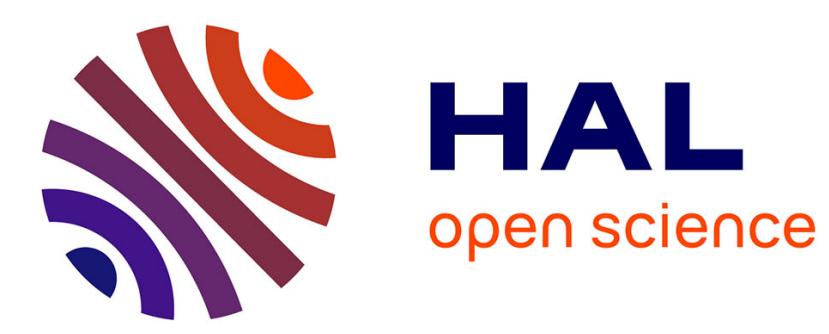

\title{
Statistical Discrimination in a Search Equilibrium Model: Racial Wage and Employment Disparities in the US
}

Bruno Decreuse, Linas Tarasonis

\section{To cite this version:}

Bruno Decreuse, Linas Tarasonis. Statistical Discrimination in a Search Equilibrium Model: Racial Wage and Employment Disparities in the US. 2016. halshs-01327961

\author{
HAL Id: halshs-01327961 \\ https://shs.hal.science/halshs-01327961 \\ Preprint submitted on 7 Jun 2016
}

HAL is a multi-disciplinary open access archive for the deposit and dissemination of scientific research documents, whether they are published or not. The documents may come from teaching and research institutions in France or abroad, or from public or private research centers.
L'archive ouverte pluridisciplinaire HAL, est destinée au dépôt et à la diffusion de documents scientifiques de niveau recherche, publiés ou non, émanant des établissements d'enseignement et de recherche français ou étrangers, des laboratoires publics ou privés. 


\section{amse}

école d'économie d'aix-marseille

aix-marseille school of economics

\section{Working Papers / Documents de travail}

Statistical Discrimination in a Search Equilibrium Model: Racial Wage and Employment Disparities in the US

Bruno Decreuse

Linas Tarasonis 


\title{
Statistical Discrimination in a Search Equilibrium Model: Racial Wage and Employment Disparities in the US*
}

\author{
Bruno Decreuse ${ }^{\dagger} \quad$ Linas Tarasonis ${ }^{\ddagger}$ \\ June 6, 2016
}

\begin{abstract}
In the US, black workers spend more time in unemployment, lose their jobs more rapidly, and earn lower wages than white workers. This paper quantifies the contributions of statistical discrimination, as portrayed by negative stereotyping and screening discrimination, to such employment and wage disparities. We develop an equilibrium search model of statistical discrimination with learning based on Moscarini (2005) and estimate it by indirect inference. We show that statistical discrimination alone cannot simultaneously explain the observed differences in residual wages and monthly job loss probabilities between black and white workers. However, a model with negative stereotyping, larger unemployment valuation and faster learning about the quality of matches for black workers can account for these facts. One implication of our findings is that black workers have larger returns to tenure.
\end{abstract}

Keywords: Learning; Screening discrimination; Job search; Indirect inference

JEL codes: J31; J64; J71.

*We thank Katarína Borovičková, Jake Bradley, Denis Fougère, Andrea Moro, Grigorios Spanos, participants to the GEDIM workshop on gender and ethnic discrimination and the AMSE-Banque de France conference that both took place in Aix-en-Provence, the EEA annual congress in Mannheim, various meetings of the Search and Matching (SaM) network, the annual Lithuanian Conference on Economic Research, the annual conference of the Spanish Economic Association. Bruno Decreuse thanks the Institut Universitaire de France for financial support.

${ }^{\dagger}$ Aix-Marseille School of Economics (Aix-Marseille University), EHESS \& CNRS, bruno.decreuse@univ-amu.fr, http://sites.google.com/site/brunodecreuseecon/

${ }^{\ddagger}$ Aix-Marseille School of Economics (Aix-Marseille University), EHESS \& CNRS, linas.tarasonis@univ-amu.fr, http://linas.econ.lt/ 


\section{Introduction}

Compared to white male workers, black male workers earn lower wages, stay unemployed longer and lose their jobs more rapidly. Though a substantial part of such disparities can be explained by differences in observable characteristics such as age, education, marital status or location, residual wages and employment differentials are large and persist over time (see, e.g., Lang and Lehmann (2012)). These findings raise questions on the roles played by unobserved skills, i.e., skills that are undocumented in survey data but have a crucial impact on workers' performance. How are such skills distributed among blacks and whites? How much time do employers need to figure out the true productivity of a worker-job pair? Is this learning process faster for whites than for blacks?

The branch of economics addressing these questions is referred to as statistical discrimination. This type of discrimination arises when employers imperfectly observe the productivity of workers, while the distribution of productive outcomes varies across race. Since Phelps (1972), statistical discrimination takes two forms: negative stereotyping and screening discrimination. Negative stereotyping (hereafter, NS) happens when employers believe that jobs occupied by black workers are on average less productive. All blacks are attributed the mean black productivity, which generates wage redistribution among black employees, from those in highly productive jobs to those in low productive ones. Screening discrimination (hereafter, SD) occurs when employers need more time to learn the productivity of jobs occupied by black workers. These workers are seen as less employable and experience slower wage growth.

Statistical discrimination has never been evaluated within the context of a formal model predicting racial wage gaps as well as differences in the probability that an unemployed worker finds a job and the probability that an employed worker becomes unemployed. This paper aims to fill this gap. We provide a dynamic model of statistical discrimination with search frictions and employer-employee learning and then estimate its structural parameters with indirect inference. Our results shed light on a fundamental trade-off between fitting wage disparities and fitting employment ones. This leads us to a different perspective on SD: the learning process is likely faster with blacks than with whites, a phenomenon we refer to as anti-screening discrimination (anti-SD).

We first begin our analysis by presenting several empirical regularities in Section 2. Specifically, we use the Current Population Survey and focus on prime-aged 
low-skilled male workers to describe the black-white wage and employment disparities. We compute the job-finding and job-separation rates of blacks and whites following Shimer (2012). The job-finding and job loss rate differentials are above $30 \%$, i.e., blacks spend $30 \%$ more time in unemployment and are $50 \%$ more likely to lose their job in the following month. We then compute residual wages using a Mincer wage regression. We find the quantile differentials of the residual wage distributions are large - the wage gap amounts to 14 percents for both entry wages and unconditional wages - and increasing, i.e., residual wage disparities are larger in levels at the top than at the bottom of the wage distribution.

We then proceed to our theoretical model, presented in Section 3, which draws from Moscarini (2005) who introduces job turnover in the spirit of Jovanovic (1984) in an equilibrium search unemployment framework. Each match between ex-ante identical workers and firms is characterized by an unobserved match quality that can be high or low. All worker-firm pairs start with a probability of being in a highquality match and the true match quality is gradually learnt over time by observing output realizations. Job loss occurs when a worker-firm pair learns their match is sufficiently likely to be of low quality. Wage bargaining over the match surplus implies there is a mapping from the ergodic distribution of posterior beliefs about match quality to the stationary wage distribution.

In our model we introduce two groups of workers, blacks and whites, and group-specific distributions of observed and unobserved skills. To account for hiring discrimination, prior beliefs about the quality of matches are drawn from a distribution with a continuous support. This distribution is allowed to be different between blacks and whites to reflect differences in unobserved heterogeneity between the two groups. As a consequence, the model predicts job-finding, job loss and the wage distribution for both groups of workers.

In Section 4, we use the simulated method of moments to estimate our model. We target moments characterizing labor market outcomes for both groups, mean monthly job-finding and job loss probabilities, quantiles of the unconditional wage distribution, and quantiles of the entry wage distribution, to obtain two main results.

On the one hand, statistical discrimination, as portrayed by NS and SD, fails to match simultaneously the properties of the quantile differentials and those of the job-finding and job loss probability differentials. In particular, NS predicts globally decreasing quantile differentials and small job loss differential, whereas SD predicts increasing quantile differentials and higher job loss for whites. The in- 
tuition for this result is straigforward and goes beyond the particularities of our model: when learning about match quality is faster for whites, these workers benefit from higher wage growth (high-quality matches are rapidly revealed), but also experience shorter job durations (low-quality matches are also rapidly revealed).

On the other hand, we show that together with differences in the valuation of unemployment between blacks and whites, statistical discrimination can explain all of the observed empirical regularities. The resulting estimation involves NS, anti$\mathrm{SD}$ and higher utility when unemployed for blacks. Anti-SD means that output signals occuring during employment are more accurate when the worker is black. Following the previous reasoning, blacks lose their jobs faster. Then, NS guarantees that the black-white differential remains large, whereas higher unemployment valuation for blacks ensures the quantile differentials of the wage distributions are increasing.

Given the focus of the literature, anti-SD seems counter-intuitive. The screening discrimination literature mainly emphasizes the opposite. ${ }^{1}$ One recent paper, however, offers a micro foundation of anti-SD. Cavounidis and Lang (2015) study managers' incentive to monitor the different groups of workers. They show that when blacks are more often in unproductive jobs, employers have stronger incentive to monitor them.

Furthermore, anti-SD offers a new perspective on racial returns to tenure. Fryer Jr et al. (2013) estimate blacks have a return-to-tenure rate that is 1.1 percentage points higher than for whites. They explain this result with a stylized three-period model of statistical discrimination where productivity is revealed after one period. NS implies that black workers will, on average, receive lower wages than whites, which leads to larger scope for wage improvement. Our estimate with anti-SD also concludes the return to tenure is larger for blacks than for whites (by 1.7 percentage points), but for a completely different reason: anti-SD implies learning is faster for blacks.

There already exist estimates of models of statistical discrimination for the labor market, but they do not feature search unemployment. Moro (2003) develops and estimates a model of racial discrimination with complementarities between skilled and unskilled workers, whereas Gayle and Golan (2012) focus on gender gaps. Both papers abstract from search frictions and do not account for racial differences

\footnotetext{
${ }^{1}$ For example, Ritter and Taylor (2011) have an efficiency wage model rationalizing racial unemployment disparities in which performance observability during employment is better for whites than for blacks. They relate this assumption to the theory of language discrimination (Lang, 1986).
} 
in unemployment duration and job separation.

By contrast, there is a substantial literature offering estimates of taste-based discrimination in search unemployment models. These models follow Becker (1971) and aim to disentangle the respective roles played by racial prejudice and unobserved worker heterogeneity in the labor market outcomes of different demographic groups: Black (1995), Eckstein and Wolpin (1999), Bowlus and Eckstein (2002), Borowczyk-Martins et al. (2014), for racial discrimination, but also Flabbi $(2010 a, b)$ for gender discrimination. Our approach does not aim to disentangle prejudice from unobserved worker heterogeneity, but we are not necessarily inconsistent with this literature. Indeed, NS may reflect, in addition to differences in productivity of the members of a particular group, existence of employers with discriminatory tastes.

More generally, search and matching models provide an interesting framework to study discrimination. In the spirit of Arrow (1973), several papers show discrimination can arise in equilibrium despite employers having no taste for discrimination and blacks and whites having similar characteristics. ${ }^{2}$ We do not explore the rich possibilities offered by such models. Instead, we draw from the framework of Phelps (1972) where skills are exogenously different between blacks and whites, and output observability varies across ethnic groups.

\section{Evidence}

In this section we summarize key differences in labor market outcomes of blacks and whites. Our analysis focuses on job-finding and job loss probabilities, as well as residual wages. All these facts will be consistent with the model presented in Section 3 and estimated in Section 4.

Data.-We use Basic Monthly Data of the Current Population Survey (CPS) from January 2003 to December 2008 and limit the sample to individuals who declare themselves to be either black or white males. For homogeneity, we only consider individuals without college education between the ages of 25 and 55 and we focus

\footnotetext{
${ }^{2}$ In Rosén (1997), employers have private information on match-specific productivity. Discriminated Blacks apply for low-quality matches, thereby creating the type of belief that leads employers to discriminate them. In Mailath et al. (2000), employers can direct their search towards Blacks or Whites, whereas workers make a pre-market investment in skills. If employers do not send offers to Blacks, then these workers invest less in human capital, justifying employers' behavior. In Holden and Rosén (2014), match quality is random and workers in bad matches search on the job. As dismissal is costly, employers trapped in a bad match hope that the worker finds another job very rapidly. Now, if employers discriminate against Blacks, these workers find alternative jobs less rapidly, and thus become less attractive to employers.
} 
on full-time workers in nonagriculture private sectors, and exclude self-employed workers.

Transition probabilities.-To measure the average monthly job loss probability and the average monthly job-finding probability, we follow Shimer (2012) and suppose that all workers of a given group have the same job-finding and job separation rates and ignore movements in and out of the labor force. The method uses monthly measures of the number of employed and unemployed workers as well as the number of unemployed workers with zero to four weeks duration of each group. The details are explained in Appendix A.

Figure 1: The ins and outs of unemployment

(a) Job-finding probability

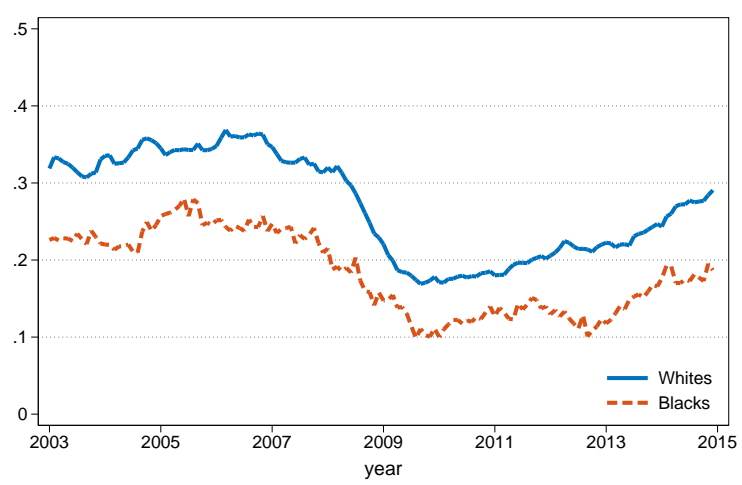

(b) Job loss probability

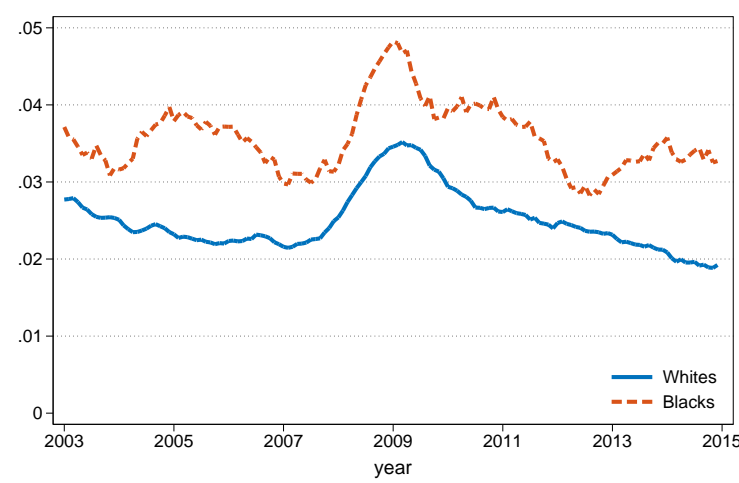

Notes.- Prime-age men with no college, 2003m1-2014m12, 12 month moving average of monthly data. Source: Current Population Survey and authors' calculations.

Figure I shows the monthly job-finding and employment exit probabilities over an enlarged period that also includes the Great Recession. Several facts about racial differences in labor market transition probabilities stand out. First, a typical black unemployed worker is on average 30\% less likely to find a job in a given month over the observed period. The racial gap in the job-finding probability is relatively stable over the businness cycle. Second, black workers are 50\% more likely to become unemployed in a given month than white workers. The racial gap in separation rates appears to be less stable over time, however, it is mainly due to the less precise estimates of the separation rate of black workers. Finally, as can be observed in Figure 1 , the transition rates are relatively stable during the pre-crisis period that we use for our estimation.

Residual wages.- To construct residual wages, we account for characteristics that are not modelled by our theory. We thus omit black workers and workers with tenure because their effects will be precisely modelled in the next section. To obtain 
the returns to explanatory variables other than race and tenure, we estimate a reduced-form wage regression on a subset of newly hired white workers:

$$
\ln w_{j}=A_{j} \Gamma+\epsilon_{j}
$$

where $w_{j}$ is the real hourly wage of a newly hired white individual $j$ and $\epsilon_{j}$ is the residual. $A_{j}$ is a vector of individual characteristics that includes a constant term, years of schooling, age, age squared, marital status, state, occupation and industry dummies. Considering age and age squared allows us to account for the effects of experience and general human capital accumulation that our model neglects. The underlying assumption is that workers accumulate general human capital whether they are employed or not.

We use the estimated returns to characteristics, $\hat{\Gamma}$, to obtain residual wages of all workers in our sample including blacks and those with postive tenure within the firm. For individual $i$, we define the efficient wage as follows

$$
\omega_{i}=\frac{w_{i} \exp \left(-A_{i} \hat{\Gamma}\right)}{\max _{j}\left\{w_{j} \exp \left(-A_{j} \hat{\Gamma}\right)\right\}},
$$

where $w_{i}$ is the observed hourly wage, $\hat{\Gamma}$ is the vector of OLS estimates of equation (1). The normalization implies that the maximum efficient wage is equal to one. This procedure leaves us with two residual wage distributions, one for each group.

To implement this procedure we use the Merged Outgoing Rotation Groups when information on usual weekly hours/earnings is recorded. Specifically, this information is measured at the household's fourth and eighth month in the survey. To obtain hourly wages we use reported usual hourly wages when a worker is paid hourly, or usual weekly earnings divided by usual weekly hours worked otherwise. Since wages are top-coded, we only consider observations with hourly wages above $\$ 1$ and below $\$ 100$ when estimating returns to observable characteristics and we trim the top and bottom $2 \%$ of the residual hourly wage distribution for both groups. The resulting sample contains roughly 118,000 individual-year observations, of which nearly $9 \%$ correspond to blacks. We define newly hired workers as those employed during the fourth or the eighth month in the survey and nonemployed at any point previously.

Table I provides the main moments of efficient wage distributions of both groups. Again, several facts stand out. First, the median black-white wage gap is around 14 percent for both the unconditional and the entry wage distributions. Second, as can be seen in column Diff., quantile differentials of both distributions 
Table 1: Summary statistics of efficient wages

\begin{tabular}{lcccc|cccc}
\hline & \multicolumn{4}{c|}{ All jobs } & \multicolumn{4}{c}{ New jobs } \\
\cline { 2 - 9 } & Whites & Blacks & Diff. & Log-Diff. & Whites & Blacks & Diff. & Log-Diff. \\
\hline Mean & .444 & .394 & .051 & .121 & .411 & .365 & .045 & .117 \\
St.-dev. & .161 & .148 & .013 & .086 & .155 & .144 & .011 & .072 \\
Min & .181 & .161 & .019 & .113 & .181 & .169 & .012 & .070 \\
5th perc. & .232 & .204 & .027 & .126 & .218 & .199 & .019 & .091 \\
25th perc. & .323 & .286 & .037 & .122 & .296 & .261 & .035 & .126 \\
50th perc. & .415 & .361 & .054 & .139 & .377 & .328 & .049 & .139 \\
75th perc. & .536 & .473 & .064 & .126 & .492 & .439 & .053 & .115 \\
95th perc. & .761 & .701 & .060 & .082 & .727 & .677 & .051 & .072 \\
Max & 1.000 & .911 & .089 & .093 & .999 & .890 & .109 & .115 \\
\hline $\mathrm{N}$ & 107,223 & 10,698 & & & 5,146 & 633 & & \\
\hline
\end{tabular}

Notes.-Efficient wages are defined in (2). The first four columns correspond to the unconditional efficient wage distribution, the last four ones to the entry wage distribution. The third and fourth columns for both distributions, Diff. and Log-Diff., report the black-white difference and log-difference, respectively.

are strongly increasing. Having increasing quantile differentials means that wage disparities are larger in levels at the right of the distribution than at its left. Third, uncoditional distribution of wages stochastically dominates the entry wage distribution and the difference is substantial. At the median, wages in all jobs are around 1o percent lower than in new jobs for both groups of workers.

The facts we describe here are in line with the literature. Elsby et al. (2010) find quantitatively similar aggregate racial differences in unemployment inflow and outflow rates using the CPS data, whereas DellaVigna and Paserman (2005) document the job-finding rate from unemployment is about $20 \%$ lower for blacks than for whites using the National Longitudinal Survey of Youth. Wage gaps are slightly higher than usual: Lang and Lehmann (2012) summarize the evidence by stating the unexplained wage gap is in the order of 10 percentage points. However, by design our measure of residual wage dispersion does not correct for differential tenures and returns to tenure between the two groups.

To summarize, blacks find jobs less rapidly, their jobs last shorter and differential quantiles are increasing. The rest of the paper is devoted to explaining these facts. Section 3 presents a dynamic model of statistical discrimination with employer-employee learning and search frictions, whereas Section 4 describes its estimation. 


\section{Theory}

Our model draws from Moscarini (2005) who introduces job turnover in the spirit of Jovanovic (1984) in a Mortensen and Pissarides (1994) equilibrium search unemployment framework. To this, we add two groups of workers with different productive abilities, different prior beliefs on the quality of matches, and different output observability. We first present the model and then focus on mechanisms and outcomes of discrimination.

All proofs lie in the Appendix D.

\subsection{Model}

Assumptions.-The labor market is populated by a continuum of risk-neutral workers of measure one and a continuum of firms that post vacancies. The labor market is characterized by random search frictions. Firms are identical, whereas workers differ in observable type $\alpha$ and demographic group $i=B, W$, where $B$ stands for black and $W$ for white. The measure of each group is $m_{i}$, such that $m_{B}+$ $m_{W}=1$, and the distribution of type is group-specific: the cumulative distribution function (cdf) is $\Psi_{i}$ and the associated probability density function (pdf) is $\psi_{i} \equiv \Psi_{i}^{\prime}$.

The endogenous measure of unemployed workers in group $i$ is $u_{i}$. When unemployed workers of type $\alpha$ obtain utility flow $b_{i} \alpha$ and receive job offers at rate $\lambda$, irrespective of their type. Then the firm and the worker decide if they form a match. Employed workers lose their job at exogenous rate $\delta$ and also when the match surplus falls below zero. Though Moscarini (2005) extends his model to onthe-job search, we do not allow for it. The idea of our paper is to isolate learning as the only factor of wage growth and see how far statitical discrimination can go to explain employment and wage disparities between blacks and whites. Therefore we do not consider alternative mechanisms on the premise that they are similar for blacks and whites. ${ }^{3}$

The output of a firm-worker pair depends on workers' type and match quality $\mu$ according to $y_{\alpha \mu}=\alpha \mu$. Match quality can take two values: the match is good when $\mu=\mu_{H}$ and bad when $\mu=\mu_{L}<\mu_{H}$. Match quality is imperfectly observed at hiring and gradually learnt with tenure. When a firm and a worker meet, they draw a common signal $p_{0} \in[0,1]$ about the average productivity of the match. The

\footnotetext{
${ }^{3}$ The computation of efficient wages provides a good illustration of this idea. Entry wages are regressed on age and age squared to capture the effects of labor pmarket experience. Such effects, by assumption, are the same for blacks and whites. On the-job-search and human capital accumulation are discussed in Section 4.4, which examines the robustness of our results.
} 
signal is such that $p_{0}=\operatorname{Pr}\left(\mu=\mu_{H}\right)=1-\operatorname{Pr}\left(\mu=\mu_{L}\right)$. In Moscarini (2005), this signal takes a single value. To account for hiring discrimination and for a nondegenerate wage distribution of those newly hired, we assume the signal is drawn from the group-specific cdf $G_{i}^{0}$ with associated pdf $g_{i}^{0} \equiv G_{i}^{0 \prime}$.

Match productivity is subject to an additional source of idiosyncratic noise. The cumulative output of a match of tenure $t$ follows a Brownian motion with drift $\alpha \mu$ and type-specific variance $\alpha^{2} \sigma_{X i}^{2}$ :

$$
X_{\alpha i t}=\alpha\left(\mu t+\sigma_{X i} Z_{t}\right) \sim \mathcal{N}\left(\alpha \mu t, \alpha^{2} \sigma_{X i}^{2} t\right),
$$

where $Z_{t}$ is a Wiener process that keeps $\mu$ hidden. Given log-linearity in $\alpha$, the variance-to-output ratio is type-independent.

After observing flow match output, $d X_{\alpha i t}$, firms and workers update their belief with regard to match quality using Bayes' rule. Let $p_{\text {xit }}$ be the probability that the match is good. Wonham (1964) shows that $p_{\text {ait }}$ follows a diffusion process:

$$
d p_{\alpha i t}=\sigma_{p i}\left(p_{\alpha i t}\right) d \bar{Z}_{\alpha i t}
$$

where

$$
\sigma_{p i}(p)=p(1-p) \frac{\mu_{H}-\mu_{L}}{\sigma_{X i}}
$$

is the diffusion parameter and

$$
d \bar{Z}_{\alpha i t}=\frac{d X_{\alpha i t}-p_{\alpha i t} \alpha \mu_{H} d t-\left(1-p_{\alpha i t}\right) \alpha \mu_{L} d t}{\alpha \sigma_{X i}}
$$

is the innovation process, i.e., the normalized difference between realized and unconditionally expected flow output. The variable $\bar{Z}_{\alpha i t}$ follows a standard Wiener process. Note that $d X_{\alpha i t}$ is log-linear in worker type $\alpha$ and so equations (4)-(6) imply that beliefs depend on worker group and job tenure, but not on worker type.

Value functions.-Let $w_{\alpha i}(p)$ be the wage and $W_{\alpha i}(p)$ be the value of holding a job when the belief on match quality is $p$. Also let $U_{\alpha i}$ denote the worker's value of unemployment and $J_{\alpha i}(p)$ be the value of a firm employing this worker.

The workers' values solve the Hamilton-Jacobi-Bellman (HJB) equations:

$$
\begin{gathered}
r U_{\alpha i}=b_{i} \alpha+\lambda \int \max \left\{W_{\alpha i}(p)-U_{\alpha i}, 0\right\} d G_{i}^{0}(p), \\
r W_{\alpha i}(p)=w_{\alpha i}(p)+\frac{1}{2} \sigma_{p i}^{2}(p) W_{\alpha i}^{\prime \prime}(p)+\delta\left[U_{\alpha i}-W_{\alpha i}(p)\right],
\end{gathered}
$$

The value of opening a vacancy is arbitrarily set to zero. In Appendix B, we close the model and introduce a standard constant returns to scale matching function 
and costly entry for firms. The value of a filled job with belief $p$ solves the following HJB equation:

$$
r J_{\alpha i}(p)=\alpha \bar{\mu}(p)-w_{\alpha i}(p)+\frac{1}{2} \sigma_{p i}^{2}(p) J_{\alpha i}^{\prime \prime}(p)-\delta J_{\alpha i}(p),
$$

where $\bar{\mu}(p) \equiv p \mu_{H}+(1-p) \mu_{L}$ is the expected flow output.

Equilibrium wages and reservation values.-Conditional on belief $p$, the equilibrium wage is pinned down by a generalized Nash bargaining solution so that

$$
W_{\alpha i}(p)-U_{\alpha i}=\beta S_{\alpha i}(p),
$$

where $\beta \in[0,1]$ is the worker' bargaining power and $S_{\alpha i}(p) \equiv W_{\alpha i}(p)-U_{\alpha i}+J_{\alpha i}(p)$ is the total match surplus.

Match formation and dissolution obey the same optimal stopping strategy. To ensure the threshold belief $\underline{p}_{\alpha i}$ is nontrivial, we assume the following parametric restrictions hold:

$$
\mu_{H}>b>\mu_{L}-\beta \lambda \frac{\mu_{H}-\mu_{L}}{r+\delta} \int_{0}^{1} p d G_{i}^{0}(p) .
$$

The first inequality states that flow output in a good match must be larger than the utility flow derived from unemployment. If not, the match surplus is negative. The second inequality states that the utility flow derived from unemployment must be sufficiently large. Otherwise, all meetings give birth to employment relationships and hiring discrimination does not take place.

Using (8) and (9), we can rewrite the total surplus as the following second-order differential equation:

$$
S_{\alpha i}(p)=\frac{\alpha \bar{\mu}(p)+\frac{1}{2} \sigma_{p i}^{2}(p) S_{\alpha i}^{\prime \prime}(p)-r U_{\alpha i}}{r+\delta},
$$

subject to value matching, $S_{\alpha i}\left(\underline{p}_{\alpha i}\right)=0$, and smooth pasting, $S_{\alpha i}^{\prime}\left(\underline{p}_{\alpha i}\right)=0$. Following Moscarini (2005), we solve this differential equation and obtain:

$$
S_{\alpha i}(p)=c_{\alpha i} p^{\frac{1}{2}-\sqrt{\frac{1}{4}+2 \frac{r+\delta}{s_{i}^{2}}}}(1-p)^{\frac{1}{2}+\sqrt{\frac{1}{4}+2 \frac{r+\delta}{s_{i}^{2}}}}+\frac{\alpha \bar{\mu}(p)-r U_{\alpha i}}{r+\delta}
$$

where $s_{i} \equiv\left(\mu_{H}-\mu_{L}\right) / \sigma_{X i}$ is the signal-to-noise ratio. The coefficient $c_{\alpha i}$ and the optimal stopping belief $\underline{p}_{\alpha i}$ solve the system of value matching and smooth pasting equations. Existence and uniqueness of the solution is given in Appendix C. The resulting match surplus increases with belief $p \in\left[\underline{p}_{\alpha i} 1\right]$.

Nash bargaining implies $\beta J_{\alpha i}^{\prime \prime}(p)=(1-\beta) W_{\alpha i}^{\prime \prime}(p)$. Using this fact yields a simple expression for the equilibrium wage:

$$
w_{\alpha i}(p)=\beta \alpha \bar{\mu}(p)+(1-\beta) r U_{\alpha i}
$$


which is linearly increasing in belief $p$.

We plug the match surplus solution (13) into the value of unemployment (7), use the Nash bargaining solution (10) and obtain the return to search:

$$
r U_{\alpha i}=\frac{b \alpha+\beta \lambda \int_{p \geq \underline{p}_{\alpha i}}\left[(r+\delta) c_{\alpha i} p^{\frac{1}{2}-\sqrt{\frac{1}{4}+2 \frac{r+\delta}{s_{i}^{2}}}}(1-p)^{\frac{1}{2}+\sqrt{\frac{1}{4}+2 \frac{r+\delta}{s_{i}^{2}}}}+\alpha \bar{\mu}(p)\right] d G_{i}^{0}(p)}{r+\delta+\beta \lambda\left(1-G_{i}^{0}\left(\underline{p}_{\alpha i}\right)\right)} .
$$

Lemma (WORKER TYPE HETEROGENEITY) The following statements hold for all $p \in[0,1]$ and all $i=B, W$ :

(i) the functions $U_{\alpha i}, W_{\alpha i}, J_{\alpha i}$ and $w_{\alpha i}$ are proportional to $\alpha$, i.e., $U_{\alpha i}=\alpha U_{i}$, $W_{\alpha i}(p)=\alpha W_{i}(p), J_{\alpha i}(p)=\alpha J_{i}(p), w_{\alpha i}(p)=\alpha w_{i}(p)$;

(ii) the belief threshold $\underline{p}_{\alpha i}$ does not depend on worker type, i.e., $\underline{p}_{\alpha i}=\underline{p}_{i}$.

Worker type heterogeneity has simple effects on model outcomes. In particular, wages are log-linear in $\alpha$ and the optimal stopping belief does not depend on $\alpha$. These properties justify our procedure to cosntruct residual wages. Wage loglinearity implies we can isolate efficient wages by mean of a Mincer regression on newly hired whites, whereas the independence of the threshold belief vis-à-vis $\alpha$ guarantess the job-finding and job loss rates do not vary within groups.

Ergodic belief distribution.-Let $g_{i}(p)$ be the unnormalized pdf of the ergodic belief distribution among workers of group $i$. For beliefs below the threshold $\underline{p}_{i}$ this density is $g_{i}(p)=0$. For beliefs above the threshold, the Kolmogorov forward equation describes its motion. Imposing stationarity we obtain:

$$
0=\partial_{t} g_{i}(p)=\partial_{p p}\left(\frac{1}{2} \sigma_{p i}^{2}(p) g_{i}(p)\right)+\lambda u_{i} g_{i}^{0}(p)-\delta g_{i}(p)
$$

where $u_{i}$ is the measure of unemployed workers. The first term balances all flows due to learning. The second term is the flow of workers at $p$ from unemployment. The last term captures the attrition due to exogenous separation.

The forward equation is subject to two boundary conditions. The first condition states that the mass of workers above $\underline{p}_{i}$ is equal to the mass of employees, i.e., $\int g_{i}(p) d p=m_{i}-u_{i} \in\left[0, m_{i}\right]$. Moscarini (2005) names the second condition no time spending at $\underline{p}_{i}$ (NTS): $\frac{1}{2} \sigma_{p i}^{2}\left(\underline{p}_{i}\right) g_{i}\left(\underline{p}_{i}\right)=0$. As $\sigma_{p i}^{2}\left(\underline{p}_{i}\right) \neq 0$ for $\underline{p}_{i}>0$, the NTS condition implies that $g_{i}\left(\underline{p}_{i}\right)=0$. Therefore the density of the belief distribution must be zero at its lower bound. 
Hereafter, we suppose there exist $A<\infty$ and $a>-1$ such that $\lim _{p \rightarrow 1} g_{i}^{0}(p)(1-$

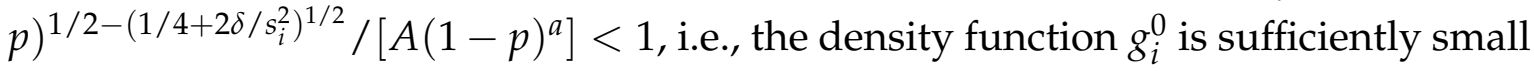
in the neighborhood of $p=1$.

Proposition 1 (ERgodic belief Distribution). Let $v_{i}=\left(1 / 4+2 \delta / s_{i}^{2}\right)^{1 / 2}, i=B, W$. For all $p \geq \underline{p}_{i^{\prime}}$

$$
\begin{aligned}
g_{i}(p)= & \lambda u_{i}[p(1-p)]^{-3 / 2-v_{i}} /\left(v_{i} s_{i}^{2}\right) \times \\
& \left\{p^{2 v_{i}} \int_{p}^{1} g_{i}^{0}(x) x^{1 / 2-v_{i}}(1-x)^{1 / 2+v_{i}} d x\right. \\
& \left.+(1-p)^{2 v_{i}}\left(k_{i}-\int_{p}^{1} g_{i}^{0}(x) x^{1 / 2+v_{i}}(1-x)^{1 / 2-v_{i}} d x\right)\right\},
\end{aligned}
$$

with

$$
k_{i}=\int_{\underline{p}_{i}}^{1} g_{i}^{0}(x) x^{1 / 2+v_{i}}(1-x)^{1 / 2-v_{i}} d x-\left(\frac{\underline{p}_{i}}{1-\underline{p}_{i}}\right)^{2 v_{i}} \int_{\underline{p}_{i}}^{1} g_{i}^{0}(x) x^{1 / 2-v_{i}}(1-x)^{1 / 2+v_{i}} d x .
$$

This (unnormalized) pdf generalizes Moscarini (2005) to the case of any nondegenerate prior distribution. As in Moscarini, the density is such that $g_{i}\left(\underline{p}_{i}\right)=0$ and $g_{i}(1)=0$ when $\delta>s_{i}^{2}$. Otherwise, $\lim _{p \rightarrow 1} g_{i}(p)=\infty$. Thus the exogenous component of job destruction must be sufficiently large to avoid cases with a large concentration of workers around the highest possible beliefs. Lastly, $g_{i}\left(\underline{p}_{i}\right)=0$ and $g(1)=0$ does not imply single-peakedness, which depends on properties of the prior distribution.

Given $g_{i}$, the corresponding normalized pdf is obtained by dividing by the mass of workers in employment. Namely, let $\tilde{g}_{i}$ be the normalized pdf of the ergodic belief distribution and $\tilde{G}_{i}$ be the corresponding cdf. We have $\tilde{g}_{i}(p)=$ $g_{i}(p) / \int g_{i}(a) d a$ and $\tilde{G}_{i}(p)=\int_{a \leq p} \tilde{g}_{i}(a) d a$.

Stationary wage distribution.-As explained above, wages are linear functions of beliefs, i.e. $w_{\alpha i}(p)=\beta \alpha \bar{\mu}(p)+(1-\beta) r U_{\alpha i}$. We define $\omega_{i}=w_{\alpha i} / \alpha$ as the efficient wage and $\Delta \omega(p) \equiv \omega_{W}(p)-\omega_{B}(p)$ as the black-white efficient wage differential conditional on belief $p$. The efficient wage differential measures wage discrimination because it focuses on two seemingly identical workers who hold a job characterized by the same belief on match quality.

We also define $F_{i}$ as the group-i-specific efficient wage distribution. By definition, $F_{i}(\omega)=\operatorname{Pr}\left[\omega_{i} \leq \omega \mid i\right]$. We compute the different quantiles of the distribution as follows: for $q \in[0,1], \omega_{i q}=F_{i}^{-1}(q)$ is the $q$-th quantile of the group-i-specific 
wage distribution. Lastly, $z(q) \equiv \omega_{W q}-\omega_{B q}$ is the black-white quantile differential, or quantile differential for short.

The quantiles of the wage distribution are such that $\omega_{i q}=\beta\left(\mu_{H}-\mu_{L}\right) \tilde{G}_{i}^{-1}(q)+$ $(1-\beta) r U_{i}+\beta \mu_{L}$. Therefore the quantile differential is

$$
z(q)=\beta\left(\mu_{H}-\mu_{L}\right)\left[\tilde{G}_{W}^{-1}(q)-\tilde{G}_{B}^{-1}(q)\right]+(1-\beta) r\left(U_{W}-U_{B}\right) .
$$

The first term is the difference in belief quantile. This term depends on the threshold beliefs of the two groups, the group-specific variances of output noise, the rates at which worker-firm pairs learn match quality, and the job separation rates. It is positive when the ergodic belief distribution of whites stochastically dominates at first order the distribution of blacks. The second term depends on the differential return to search. It is positive when whites fare better than blacks in the labor market.

By construction, $z(1)=(1-\beta) r\left(U_{W}-U_{B}\right)$ and $z(0)=\beta\left(\mu_{H}-\mu_{L}\right)\left(\underline{p}_{W}-\underline{p}_{B}\right)+$ $(1-\beta) r\left(U_{W}-U_{B}\right)$. The top quantile differential mirrors the outside option differential. The bottom quantile differential also reflects differential selection through the differential belief threshold.

\subsection{Discrimination}

We now turn to potential differences between blacks and whites conditional on type $\alpha$. Hereafter, we refer to efficient wages as being simply wages. We consider the two aspects of statistical discrimination, i.e., negative stereotyping (NS) and screening discrimination (SD). We also study unemployment valuation (UV) heterogeneity because this factor is important in the next section. In this presentation, blacks are supposedly exposed to discrimination and higher unemployment valuation.

Negative stereotyping.-In this case, employers hold negative (rational) beliefs about the ability of black workers to form a good match.

Assumption 1 (Stochastic Dominance): The distribution $G_{W}^{0}(p)$ stochastically dominates the distribution $G_{B}^{0}(p)$ at first order, i.e., $G_{B}^{0}(p) \geq G_{W}^{0}(p)$ for all $p \in[0,1]$ and there is $\tilde{p} \in\left[\underline{p}_{W^{\prime}}, 1\right]$ such that $G_{B}^{0}(\tilde{p})>G_{W}^{0}(\tilde{p})$. Moreover, $\sigma_{X B}=\sigma_{X W}=\sigma_{X}$ and $b_{B}=b_{W}=b$.

Stochastic dominance is a simple way to describe prior heterogeneity between groups. Black workers tend to draw lower initial beliefs on match quality. The origin of such a differential is not discussed here. 
Proposition 2 (Negative stereotyping). Under Assumption 1, the following statements hold:

A. Return to search: $r U_{W}>r U_{B}$.

B. Employment disparities:

(i) $1>\underline{p}_{W}>\underline{p}_{B}>0$;

(ii) the job-finding rate differential is $\Delta j f r=\lambda\left[G_{B}^{0}\left(\underline{p}_{B}\right)-G_{W}^{0}\left(\underline{p}_{W}\right)\right]$ and may be positive or negative;

(iii) the job-loss rate differential is $\Delta j l r=\frac{1}{2}\left[\sigma_{p}^{2}\left(\underline{p}_{B}\right) \tilde{g}_{B}^{\prime}\left(\underline{p}_{B}\right)-\sigma_{p}^{2}\left(\underline{p}_{W}\right) \tilde{g}_{W}^{\prime}\left(\underline{p}_{W}\right)\right]$ and may be positive or negative.

C. Wage disparities:

(i) for all $p \in\left[\underline{p}_{W^{\prime}} 1\right]$, the wage differential is $\Delta \omega(p)=(1-\beta) r\left(U_{W}-U_{B}\right)>0$;

(ii) the quantile differential is such that $z(0)>z(1)>0$.

Part A shows that whites enjoy a larger return to search. Matches with whites are more productive on average. Therefore wage and employment expectations are better for these workers.

Part B describes the ambiguous impacts of NS on employment outcomes. (i) shows that whites are more selected than blacks into employment. That $U_{W}>U_{B}$ implies the match surplus conditional on belief $p$ is always larger for blacks than for whites. Therefore the lowest belief compatible with nonnegative surplus is larger for whites. (ii) shows that the job-finding rate differential has ambiguous sign. Whites have a better prior distribution, which improves their job-finding rate, but are also more selected, which reduces their chance of finding a job. (iii) shows the job loss rate differential also has an ambiguous sign. The flow of employees who cross the belief threshold $\underline{p}_{i}$ depends on the variance of the learning process $\sigma_{p}^{2}$ and on the slope of the pdf of the belief distribution evaluated at the belief threshold. Both components differ across groups.

Part C features the non-ambiguous impacts of NS on wage outcomes. (i) shows that blacks are discriminated against: the wage differential reveals the outside option differential benefiting to whites. (ii) shows that the associated quantile differentials are positive. Whites have a better belief distribution and a higher return to search. The former effect is especially strong at the bottom of the distribution but disappears at its top where there is no uncertainty on match quality. Therefore NS is better at explaining wage disparities at the bottom of the wage distribution than at the top. 
To summarize, ex-ante differences in prior distributions have ambiguous impacts on employment outcomes and nonambiguous effects on wage outcomes. In particular, they predict positive but decreasing quantile differentials. This property is at odds with the evidence reported in Section 2.

Screening discrimination.-We now suppose the precision of output signals during employment differs between blacks and whites. This hypothesis is associated to Aigner and Cain (1977) and Cornell and Welch (1996) in the context of static models. Closer to us, Ritter and Taylor (2011) provide a model of SD with employer learning.

Assumption 2 (OUTPUT OBSERVABILITY). The standard deviation of output is larger for blacks than for whites, i.e., $\sigma_{X B}>\sigma_{X W}$. Moreover, $G_{B}^{0}=G_{W}^{0}=G^{0}$ and $b_{B}=b_{W}=b$.

Employers have more difficulties to infer match quality from output signals when the worker is black. Therefore learning is faster with whites, which exposes blacks to hiring discrimination and lower wage growth.

Proposition 3 (SCREening Discrimination). Under Assumption 2, the following statements hold:

A. Return to search: $U_{W}>U_{B}$.

B. Employment disparities:

(i) $1>\underline{p}_{B}>\underline{p}_{W}>0$;

(ii) the job-finding rate differential is $\Delta j f r=\lambda\left[G^{0}\left(\underline{p}_{B}\right)-G^{0}\left(\underline{p}_{W}\right)\right]>0$;

(iii) the job-loss rate differential is $\Delta j l r=\frac{1}{2}\left[\sigma_{p B}^{2}\left(\underline{p}_{B}\right) \tilde{g}_{B}^{\prime}\left(\underline{p}_{B}\right)-\sigma_{p W}^{2}\left(\underline{p}_{W}\right) \tilde{g}_{W}^{\prime}\left(\underline{p}_{W}\right)\right]$ and may be positive or negative.

C. Wage disparities:

(i) for all $p \in\left[\underline{p}_{W^{\prime}} 1\right]$, the wage differential $\Delta \omega(p)=(1-\beta) r\left(U_{W}-U_{B}\right)>0$;

(ii) the quantile differential is such that $z(1)>\max \{z(0), 0\}$.

Part A shows that, like NS, blacks have a lower return to search. Learning has less value when the worker is black and the match surplus is smaller at given belief on match quality.

Part B (i) shows that, unlike NS, blacks are more selected than whites into employment. Job tenure provides less information on match quality when the job is occupied by a black worker. Thus employers have less incentive to hire blacks. This result implies (ii): blacks are less likely to form matches and their job-finding 
rate is smaller. (iii) shows a more intriguing result: whites may lose their jobs faster than blacks. Output signals convey more accurate information when the worker is white. Bad output signals, therefore, more often lead to match dissolution with such workers. Formally, the variance of the learning process $\sigma_{p}^{2}$ is larger for whites, i.e., $\sigma_{p B}^{2}(p)<\sigma_{p W}^{2}(p)$. Note, however, that the job loss rate differential still has ambiguous sign because it depends on the respective numbers of blacks and whites at risk of being dismissed. These numbers are defined by the slopes of the pdf of the ergodic belief distributions evaluated at belief thresholds.

Part $C$ underlines the effect of differential selection in employment on wage disparities. (i) shows that blacks receive lower wages conditional on belief on match quality. At given match quality, blacks pay the price of lower output observability. However, they are more selected than whites, which implies that the belief distribution may be better for blacks than for whites at its bottom. This is why (ii) shows that, unlike NS, the quantile differential tends to increase with quantile.

To summarize, SD can explain why discriminated workers stay longer in unemployment and receive lower wage conditional on type and belief on match quality. It also predicts the quantile differential should be increasing in quantile. However, SD also implies blacks tend to enjoy longer employment episodes, which is at odds with the empirical evidence reported in Section 2. We now illustrate this important claim through an example.

Suppose $\sigma_{X B}$ is arbitrarily large and $\sigma_{X W}=0$ so that job tenure does not provide information for blacks, whereas match quality is revealed right after hiring for whites. When $\sigma_{X B}$ is arbitrarily large, the standard deviation is $\sigma_{p B}(p)=0$ for all $p \in[0,1]$. It follows that the belief on match quality does not change with tenure. Consequently, the wage does not change with tenure and job separation only occurs for exogenous reasons. When $\sigma_{X W}=0$, the belief immediately jumps after hiring to $p=1$ if $\mu=\mu_{H}$ or $p=0$ if $\mu=\mu_{L}$. In the former case, the worker keeps the job until exogenous separation occurs. In the latter case, the worker immediately quits the job and searches for another one. As information acquisition is instantaneous, all white applicants are hired. Thus $\underline{p}_{W}=0<\underline{p}_{B}$. The job-finding rate differential is $\Delta j f r=\lambda G^{0}\left(p_{B}\right)>0$, whereas the job loss rate differential is $\Delta j l r=\lambda \int_{0}^{1}(1-p) d G^{0}(p)>0$. Therefore jobs occupied by blacks last longer.

Unemployment valuation heterogeneity.-We finally assume the utility flow derived from unemployment differs between blacks and whites. 
Assumption 3 (UnEMPLOYMENT VAlUation): The utility flow derived from unemployment is larger for blacks than for whites, i.e., $b_{B}>b_{W}$. Moreover, $G_{B}^{0}=G_{W}^{0}=G^{0}$ and $\sigma_{X B}=\sigma_{X W}=\sigma_{X}$.

As usual in the literature, a larger $b$ can be associated with a higher preference for leisure, either because blacks are less willing to work, have a larger home production, or have a better access to the informal sector. A larger $b$ can also be due to lower unemployment stigma, something understandable in a community of workers over-exposed to unemployment.

Proposition 4 (Unemployment valuation). Under Assumption 3, the following statements hold:

A. Return to search: $U_{B}>U_{W}$.

B. Employment disparities:

(i) $1>\underline{p}_{B}>\underline{p}_{W}>0$;

(ii) the job-finding rate differential is $\Delta j f r=\lambda\left[G^{0}\left(\underline{p}_{B}\right)-G^{0}\left(\underline{p}_{W}\right)\right]>0$;

(iii) the job-loss rate differential is $\Delta j l r=\frac{1}{2}\left[\sigma_{p}^{2}\left(\underline{p}_{B}\right) \tilde{g}_{B}^{\prime}\left(\underline{p}_{B}\right)-\sigma_{p}^{2}\left(\underline{p}_{W}\right) \tilde{g}_{W}^{\prime}\left(\underline{p}_{W}\right)\right]$ and may be positive or negative.

C. Wage disparities:

(i) for all $p \in\left[p_{B^{\prime}} 1\right]$, the wage differential is $\Delta \omega(p)=(1-\beta) r\left(U_{W}-U_{B}\right)<0$;

(ii) the quantile differential is such that $z(0)<z(1)<1$.

Part A shows that blacks have a larger return to search. Search frictions imply that all people spend time in unemployment. Those who benefit from larger utility flows in this state fare better.

Part B describes the implications of Assumption 3 for employment differentials. (i) shows that blacks are more selected than whites. Matching with blacks generates lower match surplus. This implies (ii): blacks are less likely to form matches and their job-finding rate is smaller. Less can be said for the job separation rate differential because, here again, it depends on the derivative of the pdf of the belief distribution at belief threshold $\tilde{g}_{i}^{\prime}\left(\underline{p}_{i}\right)$.

Part $C$ (i) shows that blacks bargain higher wages conditional on match quality. This effect combined with the fact that blacks are more selected implies (ii): the quantile differential tends to be negative and increasing in quantile. Selection does not play any role at the top quantiles where all matches are good. Therefore the wage quantile differential tends to increase with quantile. 
To summarize, higher UV for blacks can explain differences in employment outcomes. However, it also makes counterfactual predictions for wage outcomes, implying that blacks are paid more at given belief on match quality as well as on average. From an empirical perspective, UV heterogeneity is useful because it implies that the wage quantile differential increases with quantile.

\section{Structural estimation}

In this section, we present the estimation methodology, turn to estimation results and discuss the implications of our estimates for the black-white differential return to tenure.

\subsection{Econometric methodology}

Indirect inference.-Following Gourieroux et al. (1993), we estimate the model by indirect inference. It consists of a simulated method of moments (SMM) estimator, in which some of the moments are estimated from reduced-form auxiliary models. Let $\boldsymbol{\theta}$ denote the vector of structural parameters, $\boldsymbol{m}^{S}(\boldsymbol{\theta})$ be the model-generated vector of parameters of the auxiliary models and $m^{D}$ the corresponding empirical vector. The estimation procedure finds $\boldsymbol{\theta}$ such that the distance between the modelgenerated moments and their empirical counterparts is as small as possible.

Specifically, the set of estimated parameters minimizes the following function:

$$
L(\theta)=\left(\boldsymbol{m}^{D}-\boldsymbol{m}^{S}(\boldsymbol{\theta})\right)^{T} \boldsymbol{W}\left(\boldsymbol{m}^{D}-\boldsymbol{m}^{S}(\boldsymbol{\theta})\right),
$$

where $\boldsymbol{W}$ is a weighting matrix. Assuming $L_{N}(\boldsymbol{\theta})$ is differentiable and attains its global minimum at the true parameter vector $\boldsymbol{\theta}_{0}$, a minimum verifies the following first-order condition:

$$
\frac{\partial L(\boldsymbol{\theta})}{\partial \boldsymbol{\theta}}\left(\boldsymbol{\theta}_{\mathbf{0}}\right)=-2 \frac{\partial \boldsymbol{m}^{S^{T}}(\boldsymbol{\theta})}{\partial \boldsymbol{\theta}}\left(\boldsymbol{\theta}_{\mathbf{0}}\right) \boldsymbol{W}\left(\boldsymbol{m}^{D}-\boldsymbol{m}^{S}\left(\boldsymbol{\theta}_{\mathbf{0}}\right)\right)=0 .
$$

Furthermore, assuming each moment in $m^{D}$ is asymptotically normally distributed yields the following asymptotic distribution for $\hat{\theta}: 4$

$$
\sqrt{N}\left(\hat{\boldsymbol{\theta}}-\boldsymbol{\theta}_{\mathbf{0}}\right) \sim \mathcal{N}\left(\mathbf{0},\left(\boldsymbol{M}^{T} \boldsymbol{W} \boldsymbol{M}\right)^{-1} \boldsymbol{M}^{T} \boldsymbol{W} \boldsymbol{S} \boldsymbol{W} \boldsymbol{M}\left(\boldsymbol{M}^{T} \boldsymbol{W} \boldsymbol{M}\right)^{-1}\right)
$$

4By the mean value theorem for some $\overline{\boldsymbol{\theta}}$ between $\hat{\boldsymbol{\theta}}$ and $\boldsymbol{\theta}_{\mathbf{0}}$, we have $\boldsymbol{m}^{D}-\boldsymbol{m}^{S}(\hat{\boldsymbol{\theta}})=\boldsymbol{m}^{D}$ $\boldsymbol{m}^{S}\left(\boldsymbol{\theta}_{\mathbf{0}}\right)+\frac{\partial \boldsymbol{m}^{S}(\boldsymbol{\theta})}{\partial \boldsymbol{\theta}^{\prime}}(\overline{\boldsymbol{\theta}}) \times\left(\hat{\boldsymbol{\theta}}-\boldsymbol{\theta}_{\mathbf{0}}\right)$, which is substituted into the first-order condition to obtain this result. 
where $N$ is the sample size, $M$ the Jacobian matrix of the moment conditions with respect to the parameters, $\boldsymbol{M}=\frac{\partial \boldsymbol{m}^{S}(\boldsymbol{\theta})}{\partial \boldsymbol{\theta}^{T}}(\hat{\boldsymbol{\theta}})$, and $\boldsymbol{S}$ the variance-covariance matrix of the empirical moments, $\boldsymbol{S}=V\left(\sqrt{N}\left(\boldsymbol{m}^{D}-\boldsymbol{m}^{S}\left(\boldsymbol{\theta}_{\mathbf{0}}\right)\right)\right)$.

We approximate $M$ using two-sided finite differences, $S$ is obtained by bootstrapping sample moments with 500 replications, and $\boldsymbol{W}$ is the estimated covariance matrix of the moments, $\boldsymbol{W}=\boldsymbol{S}$.

Parametric assumptions. - We cannot identify all parameters. Therefore we fix some of them to standard values. The monthly discount rate $r$ is set to 0.0043 , which is equivalent to $5 \%$ per annum. Workers' bargaining power $\beta$ is arbitrarily set to $1 / 2$. When parameters $\mu_{H}, \mu_{L}, b_{W}$ and $b_{B}$ are increased by a constant term, wages increase by the same constant and labor market transitions remain unchanged. Therefore they cannot be separately identified and we need to fix at least one of them. We choose $\mu_{L}=-\mu_{H}$ and leave $b_{W}$ and $b_{B}$ free. In practice, the productivity parameter differential $\mu_{H}-\mu_{L}$ must be sufficiently large so that the model can replicate the support of the empirical (efficient) wage distribution.

We also make parametric assumptions on the prior belief distributions. We suppose $G_{B}^{0}$ and $G_{W}^{0}$ have truncated log-normal distributions on the support $\left[0, p_{\max }\right]$ with $p_{\max }<1$. For all $p \in\left[0, p_{\max }\right]$ and $i=B, W$,

$$
G_{i}^{0}(p)=\frac{1}{p \eta_{i} \sqrt{2 \pi}} \frac{\exp \left[-\left(\ln p-\gamma_{i}\right)^{2} /\left(2 \eta_{i}^{2}\right)\right]}{\Phi\left[\left(\ln p_{\max }-\gamma_{i}\right) / \eta_{i}\right]},
$$

where $\gamma_{i}$ and $\eta_{i}$ are, respectively, the location and scale parameters of the distribution, and $\phi$ and $\Phi$ are, respectively, the pdf and the cdf of the standard normal distribution. The choice of log-normal functional forms is motivated by the fact that the distributions of entry wages are actually close to log-normal. The restriction $p_{\max }<1$ guarantees that the assumption made right before Proposition 1 holds. Namely, we have $\lim _{p \rightarrow 1} g_{i}^{0}(p)(1-p)^{1 / 2-\left(1 / 4+2 \delta / s_{i}^{2}\right)^{1 / 2}} /\left[A(1-p)^{a}\right]<1$, which ensures that the top quantiles of the unconditional wage distribution are larger than the corresponding quantiles of the entry wage distribution. In practice, we set $p_{\max }=0.9$ and check that the mass of the log-normal distribution above $p_{\max }$ is negligible.

We are left with the following vector of ten parameters to estimate $\boldsymbol{\theta}=\left\{\gamma_{W}, \eta_{W}, \gamma_{B}\right.$, $\left.\eta_{B}, \sigma_{X W}, \sigma_{X B}, b_{W}, b_{B}, \lambda, \delta\right\}$. The first four relate to the distributions of prior beliefs about match quality, $\sigma_{X W}$ and $\sigma_{X B}$ determine the group-specific standard deviations of output, $b_{W}$ and $b_{B}$ are the utility flows derived from unemployment, $\lambda$ is the job offer rate common to both groups, and $\delta$ is the exogenous component of job 
separation.

Choice of moments and identification.-Here we discuss the different moments we use and how they contribute to the identification of the different parameters. The model is highly nonlinear so the discussion stays heuristic.

We emphasize employment and wage differentials between blacks and whites. Therefore we give as much weight to blacks as a group as to whites in the estimation procedure. We target 12 average labor market outcomes achieved by white workers and consider the 12 associated ethnic differentials. The 12 moments are described in Section 2 and follow the theoretical discussions in Section 3.2. As for wage outcomes, we consider five quantiles of the entry wage distribution and five quantiles of the overall wage distribution. As for employment outcomes, we consider the job-finding and job loss rates.

The quantiles and quantile differentials of the entry wage distributions are key to identify the parameters of the prior distributions $G_{B}^{0}$ and $G_{W}^{0}$. The quantiles of the unconditional wage distribution for whites are crucial to identify the standard deviation of output $\sigma_{X W}$ : the difference between the entry wage distribution and the overall distribution depends on the speed of the learning process, which is inversely related to this variance. Quantile differentials give a first piece of information with regard to the respective magnitudes of NS, SD and UV heterogeneity. Proposition 2 shows NS implies quantile differentials tend to decrease with quantiles, whereas Propositions 3 and 4 suggest the opposite pattern when there is SD or UV heterogeneity.

The job-finding rate and job-finding rate differentials allow us to identify the job offer rate $\lambda$ and the difference in probability of forming a match $G_{B}^{0}\left(\underline{p}_{B}\right)-G_{B}^{0}\left(\underline{p}_{W}\right)$. Once combined with the information derived from quantiles of entry wage distributions, this probability difference helps us to identify the threshold beliefs $\underline{p}_{B}$ and $\underline{p}_{W}$. Lastly the job separation rate and the job separation rate differential allow us to disentangle the exogenous and endogenous components of job loss. This procedure easily provides a value to the exogenous separation rate $\delta$. The difference in normalized flows of employees who cross the threshold beliefs is $\sigma_{p}^{2}\left(\underline{p}_{B}\right) \tilde{g}_{B}^{\prime}\left(\underline{p}_{B}\right)$ $-\sigma_{p}^{2}\left(\underline{p}_{W}\right) \tilde{g}_{W}^{\prime}\left(\underline{p}_{W}\right)$. The derivative of the pdf of the belief distribution $\tilde{g}_{i}^{\prime}\left(\underline{p}_{i}\right)$ depends, among other things, on the derivative of the pdf of the prior distribution evaluated in the belief threshold. The variance $\sigma_{p}^{2}\left(\underline{p}_{i}\right)=\underline{p}_{i}\left(1-\underline{p}_{i}\right) \frac{\mu_{H}-\mu_{L}}{\sigma_{X i}}$ is inversely related to the standard deviation of output $\sigma_{X i}$. Therefore we have additional information to identify the parameters of the prior distribution and the standard deviation of output. 
The estimation is not a trivial one. Blacks and whites can differ in three ways, but the estimation forces many parameters to be the same across groups: the exogenous separation rate $\delta$, the job offer rate $\lambda$, discount rate $r$, bargaining power $\beta$, output levels in a good match $\mu_{H}$ and in a bad one $\mu_{L}$. Moreover, there are trade-offs between the different moments. In particular, fitting quantiles of the unconditional wage distribution, quantiles of the entry wage distribution and job separation is challenging. The learning process determines wage growth over tenure but also affects the stationary flow of employees who lose their job through the term $\sigma_{p}^{2}$. Similarly, the prior belief distribution shapes the entry wage distribution but also impacts the latter flow through the term $\tilde{g}_{i}^{\prime}\left(\underline{p}_{i}\right)$.

\subsection{Estimation results}

Fit of the moments.-Table 2 compares the model outcomes with the empirical moments chosen for estimation. We run five specifications. The first three columns display the results when a single mechanism is at play, i.e., NS in column (1), SD in column (2) and differences in UV in column (3). Column (4) allows for both types of statistical discrimination (NS-SD). Finally, column (5) combines the three mechanisms (NS-SD-UV). Columns (6) and (7) contain the means and standard deviations of the bootstrapped moments that our estimation procedure matches. The goodness of fit of each specification is summarized by the maximized value of the criterion displayed by equation (20).

Table 2 shows two important results. On the one hand, models based on statistical discrimination alone (NS and SD) face a fundamental trade-off between fitting the quantile differentials of wage distributions and fitting the job loss differential. On the other hand, combining statistical discrimination with UV allows us to escape this trade-off.

All models fit reasonably well the different quantiles of the white wage distributions, the white job-finding probability and the white job loss probability. However, all models except the NS-SD-UV fail to reproduce the large positive and increasing quantile differentials of the unconditional wage distributions and the large jobfinding and job loss rate differentials. In columns 1 to 4 , the quantile differentials are far from the empirical ones, the job-finding rate differential is modestly positive and the job-loss rate differential is zero or negative. By contrast, the model combining NS-SD-UV in column 5 correctly fits the quantile and transition rate differentials. It slightly overestimates the job-finding rate differential (11.4 percentage 
Table 2: Fit of the moments

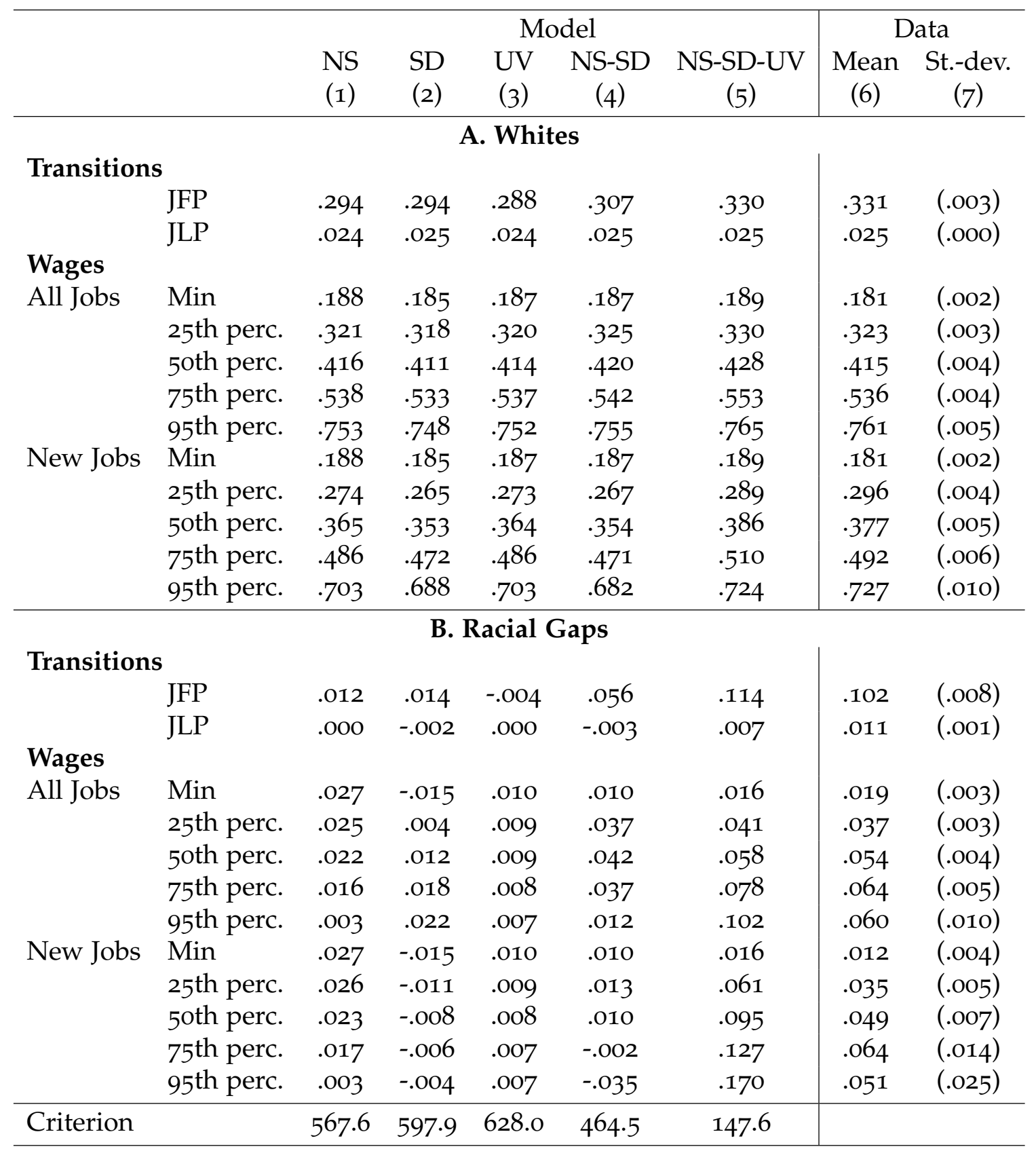

Notes.-Model fit of the five specifications: Negative Stereotyping (NS) in column (1), Screening Discrimination (SD) in column (2), differences in Unemployment Valuation (UV) in column (3), both types of statistical discrimination (NS-SD) in column (4) and the three mechanisms (NS-SD-UV) in column (5). Columns (6) and (7) contain the means and standard deviations of the bootstrapped moments with 500 replications. Transition rates are at monthly frequency, wages are hourly. Panel A. corresponds to the levels of wages of white workers. Panel B. reports the racial gaps. Wages in all jobs refer to the unconditional efficient wage distribution, wages in new jobs to the entry wage distribution. 
Table 3: Parameter Estimates

\begin{tabular}{lccccc}
\hline Parameter & $\begin{array}{c}\text { NS } \\
(1)\end{array}$ & $\begin{array}{c}\text { SD } \\
(2)\end{array}$ & $\begin{array}{c}\text { UV } \\
(3)\end{array}$ & $\begin{array}{c}\text { NS-SD } \\
(4)\end{array}$ & $\begin{array}{c}\text { NS-SD-UV } \\
(5)\end{array}$ \\
\hline $\bar{p}_{0} W$ & 0.566 & 0.556 & 0.566 & 0.557 & 0.586 \\
& $(.004)$ & $(.004)$ & $(.004)$ & $(.004)$ & $(.003)$ \\
$\bar{p}_{0} B$ & 0.556 & 0.556 & 0.566 & 0.538 & 0.516 \\
& $(.004)$ & $(.004)$ & $(.004)$ & $(.005)$ & $(.003)$ \\
$\sigma_{p_{0} W}$ & 0.083 & 0.083 & 0.084 & 0.081 & 0.081 \\
& $(.001)$ & $(.001)$ & $(.001)$ & $(.001)$ & $(.001)$ \\
$\sigma_{p_{0} B}$ & 0.089 & 0.083 & 0.084 & 0.095 & 0.070 \\
& $(.002)$ & $(.001)$ & $(.001)$ & $(.002)$ & $(.002)$ \\
$\sigma_{X W}$ & 234.48 & 217.00 & 238.22 & 193.63 & 239.54 \\
& $(6.45)$ & $(5.65)$ & $(6.68)$ & $(4.53)$ & $(8.18)$ \\
$\sigma_{X B}$ & 234.48 & 324.17 & 238.22 & 398.83 & 165.84 \\
& $(6.45)$ & $(19.13)$ & $(6.68)$ & $(28.78)$ & $(7.35)$ \\
$b_{W}$ & -2.025 & -1.910 & -1.984 & -1.951 & -2.488 \\
& $(.041)$ & $(.039)$ & $(.040)$ & $(.040)$ & $(.051)$ \\
$b_{B}$ & -2.025 & -1.910 & -2.055 & -1.951 & -0.594 \\
& $(.041)$ & $(.039)$ & $(.044)$ & $(.040)$ & $(.040)$ \\
$\lambda$ & 0.522 & 0.556 & 0.510 & 0.569 & 0.528 \\
& $(.016)$ & $(.021)$ & $(.016)$ & $(.020)$ & $(.012)$ \\
$\delta$ & 0.020 & 0.020 & 0.020 & 0.019 & 0.022 \\
& $(.000)$ & $(.000)$ & $(.000)$ & $(.000)$ & $(.000)$ \\
\hline
\end{tabular}

Notes.-Estimation by SMM of the five specifications: Negative Stereotyping (NS) in column (1), Screening Siscrimination (SD) in column (2), differences in Unemployment Valuation (UV) in column (3), both types of statistical discrimination (NS-SD) in column (4) and the three mechanisms (NS-SD-UV) in column (5). Bootstrapped standard errors in parentheses. $\overline{p_{0}} i$ and $\sigma_{p_{0} i}$ correspond to the mean and standard deviation of the group- $i$ specific prior distribution, respectively.

points against 10.2 percentage points in the data) and accounts for $65 \%$ of the job loss rate differential.

We now describe parameter estimates before explaining these results in detail.

Parameter Estimates.-Tables 3 and 4 show the parameter estimates and some of the endogenous variables. For expositional purposes, we report the mean and standard deviation of the prior distribution, as opposed to the location and scale parameters. 5

In columns 1, 2 and 4, only statistical discrimination is taken into account. The estimated parameters feature the expected situation where blacks endure both NS

5The mean $\overline{p_{0}}$ and standard deviation $\sigma_{p_{0} i}$ of the log-normal distribution with location and scale parameters $\gamma_{i}$ and $\eta_{i}$ are $\overline{p_{0}}=\exp \left(\gamma_{i}+\eta_{i}^{2} / 2\right)$ and $\sigma_{p_{0} i}=\sqrt{\exp \left(2 \gamma_{i}+\eta_{i}^{2}\right)\left(\exp \left(\eta_{i}^{2}\right)-1\right)}$. In our case, the priors have truncated log-normal distribution, however the latter formulas are good proxies due to the fact that the probability mass above the truncation point $p_{\max }$ is negligible in all of our estimations. 
Table 4: Endogenous variables

\begin{tabular}{lccccc}
\hline Variable & $\begin{array}{c}\text { NS } \\
(1)\end{array}$ & $\begin{array}{c}\text { SD } \\
(2)\end{array}$ & $\begin{array}{c}\text { UV } \\
(3)\end{array}$ & $\begin{array}{c}\text { NS-SD } \\
(4)\end{array}$ & $\begin{array}{c}\text { NS-SD-UV } \\
(5)\end{array}$ \\
\hline$\underline{p}_{W}$ & 0.526 & 0.524 & 0.526 & 0.523 & 0.526 \\
$\underline{p}_{B}$ & 0.520 & 0.531 & 0.524 & 0.528 & 0.518 \\
$g^{\prime}\left(p_{W}\right)$ & 301.13 & 297.91 & 304.77 & 266.59 & 269.07 \\
$g^{\prime}\left(\underline{p}_{B}\right)$ & 297.85 & 454.18 & 299.72 & 535.20 & 349.37 \\
$\sigma_{p W} \times 100$ & 0.532 & 0.575 & 0.523 & 0.644 & 0.520 \\
$\sigma_{p B} \times 100$ & 0.532 & 0.384 & 0.524 & 0.312 & 0.753 \\
$r U_{W}$ & 0.248 & 0.250 & 0.246 & 0.261 & 0.246 \\
$r U_{B}$ & 0.221 & 0.243 & 0.236 & 0.213 & 0.256 \\
\hline
\end{tabular}

Notes.-Endogenous variables of interest of the five specifications: Negative Stereotyping (NS) in column (1), Screening Discrimination (SD) in column (2), differences in Unemployment Valuation (UV) in column (3), both types of statistical discrimination (NS-SD) in column (4) and the three mechanisms (NS-SD-UV) in column (5).

and SD. When NS is involved as in columns 1 and 4 , whites enjoy a better prior distribution. ${ }^{6}$ When SD is involved as in columns 2 and 4 , output signals are more noisy when the worker is black. In column 3, only UV is accounted for. UV is actually larger for whites than for blacks, which explains column 3 in Table 2 displays results opposite to Proposition 4.

We now explain the trade-off between fitting the quantile differentials and fitting the job loss differential. In our data, the quantile differentials of the (efficient) wage distributions are large and increasing in quantile, whereas the job loss rate differential is substantial. Proposition 2 shows that NS predicts decreasing quantile differentials. Moreover, though generating positive job loss differential is theoretically possible, the estimated differential is nil. Proposition 3 shows that SD can predict increasing quantile differentials. However, SD also implies that whites lose their jobs more rapidly.

In column 5, statistical discrimination is combined with UV heterogeneity. The estimated parameter configuration corresponds to NS, anti-SD and larger UV for blacks. Blacks still draw their initial belief on match quality from a worse distribution than whites. However, they benefit from a faster learning process: now the standard deviation of output signals is larger for whites. Lastly, blacks enjoy higher utility flows once in unemployment.

Anti-SD guarantees that blacks lose their jobs faster, whereas NS implies that

\footnotetext{
${ }^{6}$ In column 1, the standard deviation is larger for Blacks, which implies that the white distribution does not stochastically dominate the black one at first order. Thus the pdf of the black distribution is slightly higher than the pdf of the white one in the neighborhood of $p=0.9$.
} 
the job-finding rate differential is positive and blacks are paid less than whites. According to Propositions 2 and 3, NS and anti-SD predict decreasing quantile differentials. Meanwhile Proposition 4 shows that larger UV for blacks implies increasing quantile differentials, which explains why $b_{B}>b_{W}$ in column 5 .

Anti-SD means the true match quality is easier to observe during employment when the worker is black. This result is at odds with standard assumptions in the literature. In their paper quantifying racial differences in unemployment, Ritter and Taylor (2011) argue managers face more difficulties to assess the productivity of black workers both at interview and during employment. They refer to the theory of language discrimination put forward by Lang (1986). According to this theory, blacks can be seen as speaking a different language, generating transaction costs within firms. Ritter and Taylor add that managers who had to choose between reducing the white noise or the black one would prefer reducing the white noise because whites are more numerous. Cavounidis and Lang (2015) argue against this view, thereby providing a possible rationale to the result of anti-SD. They also consider managers' incentive to supervize the different groups of workers. When blacks occupy unproductive jobs more often than whites, managers spend more resources monitoring blacks.

UV heterogeneity is here beneficial to blacks. This can be interpreted in terms of heterogenous preference for leisure, domestic production, access to the informal sector, or unemployment stigma. A controversial implication of our estimation is that blacks and whites have the same expected utility when unemployed. Thus the model can rationalize large residual disparities in terms of wage and transition rates despite the typical black worker enjoys the same utility level as the typical white worker.

In all estimates, the utility flows $b_{B}$ and $b_{W}$ obtained in unemployment are negative. In job search models, what matters is the utility differential between the employment and unemployment states and not the utility level obtained in each state. We just lose the ability to measure the unemployment utility flow in percentage of the wage.

Belief and wage distributions.-Figure 2 depicts the initial and ergodic belief distributions in two cases: NS-SD vs NS-SD-UV. The ergodic distributions are more dispersed than the initial distributions and feature fat right tails. In both cases, the threshold beliefs are very close. Blacks are slightly more selected in the NSSD case, but slightly less selected in the NS-SD-UV case. Under NS-SD, the prior distribution of blacks has a larger variance. This property extends to the ergodic 
Figure 2: Prior and ergodic belief distributions

(a) Prior belief distributions, NS-SD

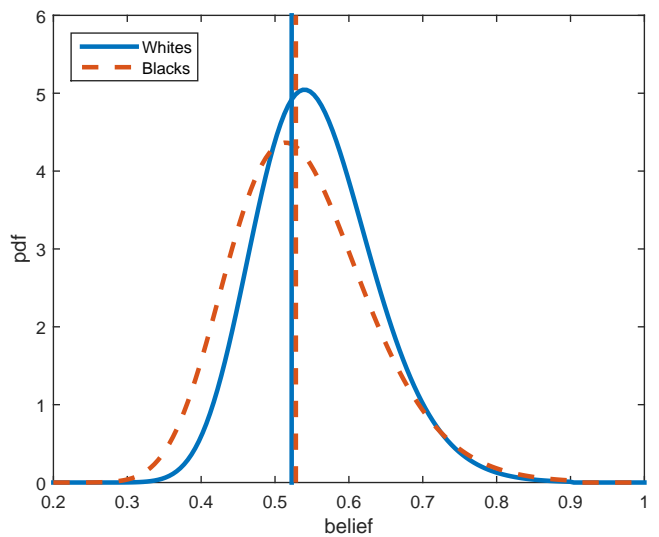

(c) Prior belief distributions, NS-SD-UV

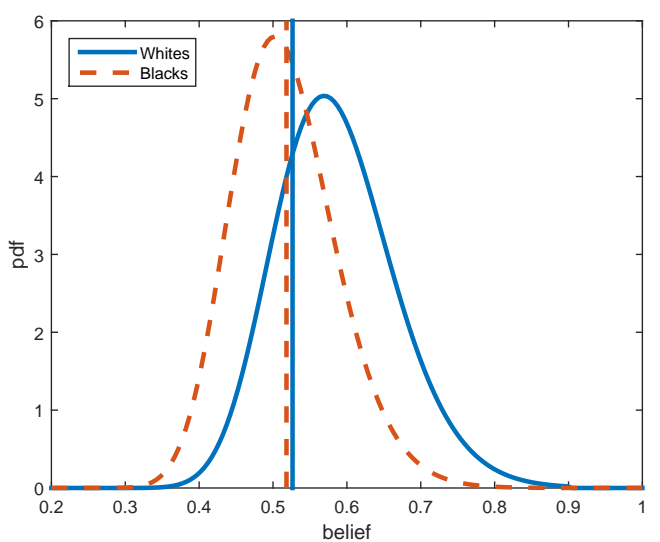

(b) Ergodic belief distributions, NS-SD

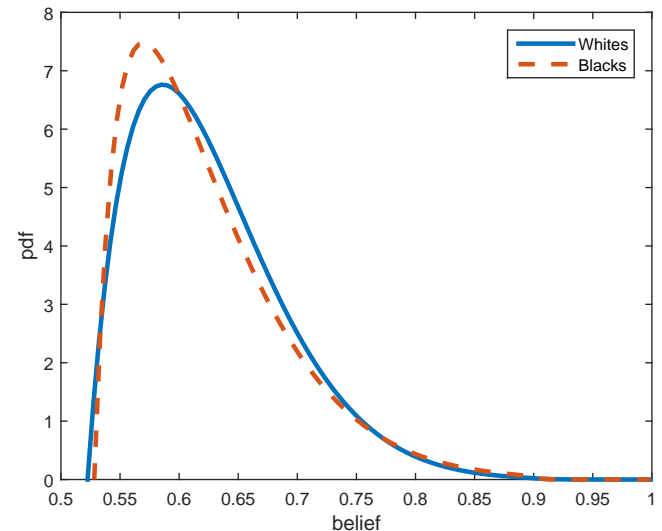

(d) Ergodic belief distributions, NS-SD-UV

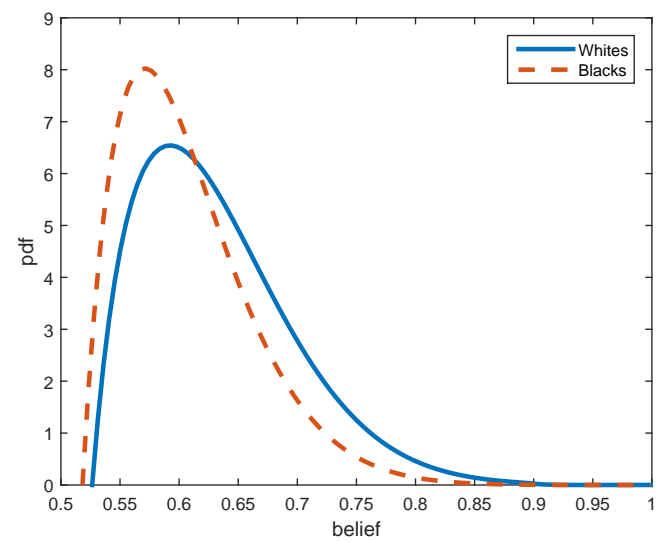

Notes.- Vertical lines correspond to threshold beliefs $\underline{p}_{W}$ and $\underline{p}_{B}$.

distribution where the pdf is slightly higher for blacks at large beliefs. Under NS-SD-UV, both the mean and the variance of the prior distribution are larger for whites. Therefore the initial and ergodic white distributions stochastically dominate at first order the corresponding black distributions.

Figure 3 shows the corresponding entry and unconditional wage distributions. They plot the predicted and empirical wage distributions in the cases of NS-SD and NS-SD-UV. In both cases, the entry wage distribution is less well fitted than the unconditional wage distribution. The estimation procedure uses efficient weighting, which implies that the moments with the largest variance receive the lowest weight in the loss function. Quantiles of the entry wage distribution are less precisely estimated because fewer workers are concerned. 
Figure 3: Fit to wage moments

(a) All jobs, NS-SD

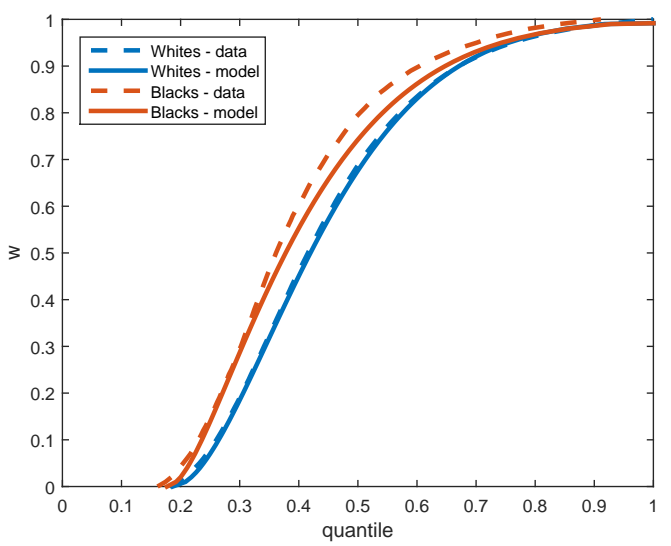

(c) All jobs, NS-SD-UV

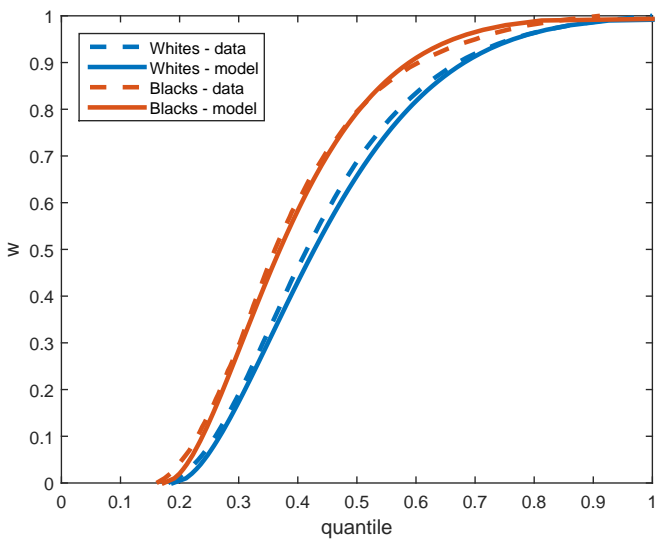

(b) New jobs, NS-SD

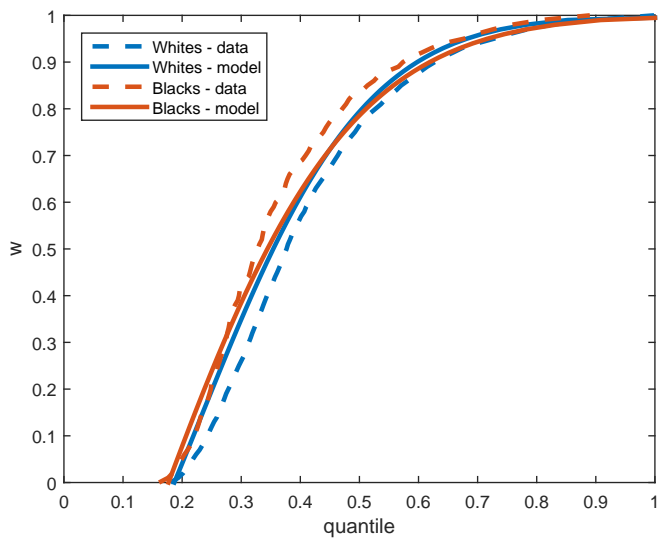

(d) New jobs, NS-SD-UV

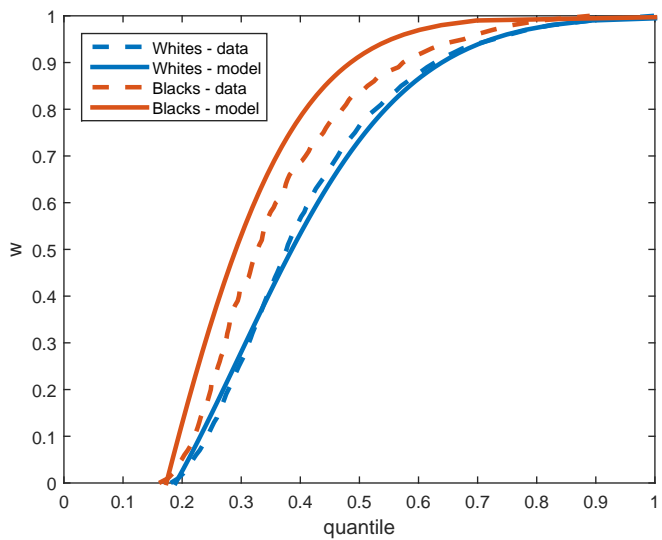

Notes.- Wages in all jobs refer to the unconditional efficient wage distribution and wages in new jobs to the entry wage distribution.

\subsection{Returns to tenure}

We conclude this section by discussing the returns to tenure for blacks and whites. Fryer Jr et al. (2013) use a dataset from the Princeton University Survey Research Center and estimate that the return to tenure is larger for blacks by 1.1 percentage points. They rationalize this result through a stylized threeperiod model of statistical discrimination. NS implies blacks are more selected than whites. Therefore the scope for wage improvement is larger for blacks than for whites and the wage gap decreases with tenure.

We simulate individual labor market histories for the different specifications of our model. We discretize time at monthly frequency and compute 500-month long histories for 25,000 individuals of each group. The details of the algorithm are 
Table 5: Black and white estimated returns to tenure on simulated data

\begin{tabular}{lccccc}
\hline & NS & SD & UV & NS-SD & NS-SD-UV \\
& $(1)$ & $(2)$ & $(3)$ & $(4)$ & $(5)$ \\
\hline Black & -.063 & .011 & -.026 & -.044 & -.204 \\
Tenure & .017 & .019 & .016 & .021 & .016 \\
Tenure $\times$ Black & .001 & -.007 & .001 & -.010 & .019 \\
Constant & -.954 & -.974 & -.956 & -.966 & -.918 \\
\hline$R^{2}$ & .032 & .026 & .026 & .035 & .097 \\
\hline
\end{tabular}

Notes.- Results of the OLS estimation of equation (22) using pooled data from the simulated individual histories as implied by the estimates of the five specifications: Negative Stereotyping (NS) in column (1), Screening Discrimination (SD) in column (2), differences in Unemployment Valuation (UV) in column (3), both types of statistical discrimination (NS-SD) in column (4) and the three mechanisms (NS-SD-UV) in column (5). Tenure is in years. Simulated data for each specification are obtained by generating 500-month long history for 25,000 individuals of each group. Total number of observations $\approx 23,000,000$ depending on specification.

provided in Appendix E. We then perform the following OLS regression:

$$
\ln w_{i \tau}=a_{0}+a_{1} \text { Black }_{i}+a_{2} \tau+a_{3} \text { Black }_{i} \times \tau+\varepsilon_{i} .
$$

Table 5 reports the estimates. Each column corresponds to a particular specification of the model. Statistical discrimination alone does not predict the narrowing of racial differences in wages with tenure, as reported by Fryer et al. Column 1 corresponds to the case advocated by Fryer et al. NS effectively implies that the return to tenure is larger for blacks. However, the estimated belief thresholds are very close to each other so that selection effects are quantitatively small. In column 4 NS is combined with SD. SD dominates selection effects induced by NS and the predicted return to tenure is larger for whites by 1 percentage point. By contrast, the combination of NS, SD and UV implies that the return to tenure is larger for blacks by 1.9 percentage points. The small $R^{2}$ in all regressions reflect that random draws on match quality account for a very large part of wages at all tenures. Moreover the wage predicted by our model is not log-linear in tenure; a log-linear regression therefore leads to systematic errors that reduce the $R^{2}$. Adding tenure squared and its interaction with the racial dummy increases the $R^{2}$ by 5 percentage points on average.

The estimates performed from the NS-SD-UV sample have the same order of magnitude as Fryer et al. However, the economic mechanism strongly differs from theirs. They emphasize selection effects induced by NS. Here selection effects can be neglected and the differential return to tenure is entirely due to anti-SD.

Figure 4a depicts the predicted log median wage differential by tenure for the NS-SD and NS-SD-UV specifications. The horizontal line is the minimum log wage 
Figure 4: Differential return to tenure and experience according to model specification

(a) Differential return to tenure

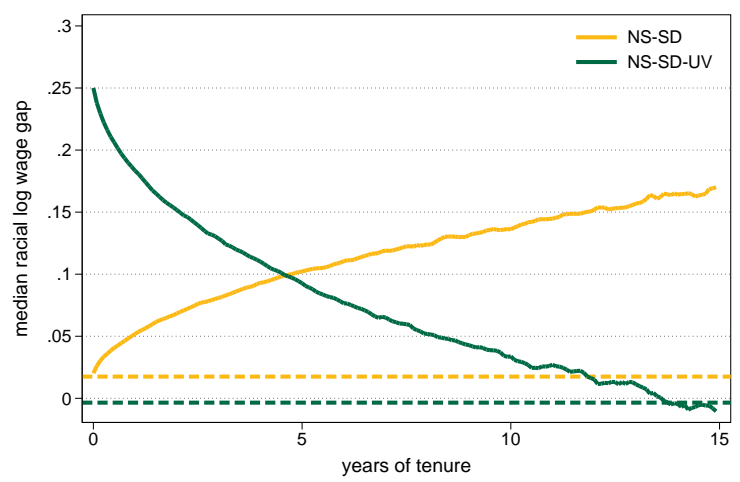

(b) Differential return to experience

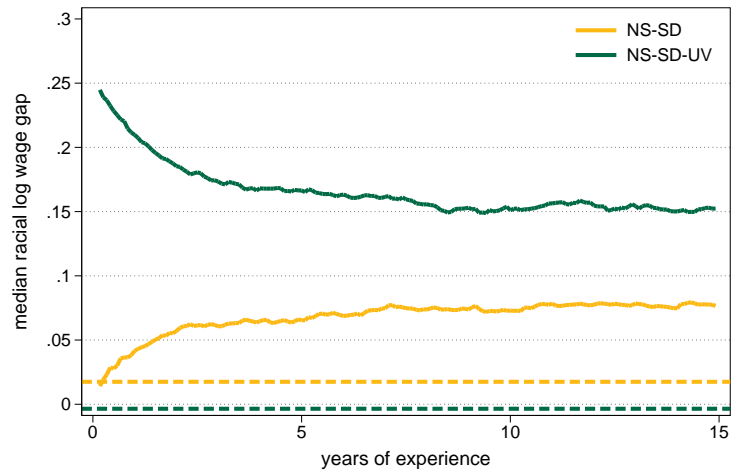

Notes. - Median log wage gap is defined as the black-white difference in median log wage by tenure. It is calculated from the simulated data obtained by generating 500-month long history for 25,000 individuals of each group. The dashed lines measure the wage gap that results from differences in workers' outside options.

differential between the two groups reflecting the differential return to search. In the NS-SD case, the median wage differential strictly increases with tenure, starting relatively low around $2.5 \%$ and reaching over $15 \%$ after 15 years. In the NS-SDUV specification, the median wage differential strictly decreases, starting relatively large around $25 \%$ and almost reaching o after 15 years. The slope of each curve decreases with tenure in absolute value. This confirms that the differential return to tenure decreases with tenure.

The differential return to tenure does not coincide with the differential return to experience because blacks and whites have different job durations. Figure $4 \mathrm{~b}$ shows the log median wage differential by experience for the NS-SD and NS-SDUV estimates. The NS-SD curve is below the NS-SD-UV curve partly reflecting the poor ability of the NS-SD case to fit the large quantile differentials of the unconditional wage distributions. In the NS-SD estimate, the job loss rate is slightly larger for whites, so that the differential return to experience is increasing but at a smaller pace than the differential return to tenure. In the NS-SD-UV specification, jobs last longer for whites, so that the differential return to experience is larger than the differential return to tenure. Overall, the predicted differential return to experience is slightly decreasing at low experience and roughly constant over 15 years.

\subsection{Robustness}

In this section, we discuss the robustness of our results. 
Efficient vs equal weighting.-We use efficient weighting, which means that less precisely estimated moments receive less weight than accurately estimated ones. Since the sample contains fewer blacks than whites, quantile differentials and transition rate differentials have less weight than quantiles and transition rates for whites. Moreover, the quantiles and quantile differentials of the entry wage distribution are also less weigthed than the quantile and quantile differentials of the unconditional distribution. In an unreported estimation, we consider equal weighting matrix. Though the results differ quantitatively, the main message remains. Statistical discrimination alone cannot simultaneously fit the large increasing differential quantiles of the unconditional wage distributions and the large transition rate differentials. The preferred estimation still involves NS, anti-SD and larger UV for blacks.

Prejudiced employers vs statistical discrimination.-We do not try to disentangle racial prejudice from unobserved heterogeneity. Negative stereotyping, therefore, combines lower skills for blacks and distaste for employing these workers. Our contribution is to quantify the contributions of such negative stereotyping and differential learning to employment and wage disparities. Identification of differential learning exploits the job loss differential and differences between entry wage and unconditional wage distributions. In this perspective, our paper is complementary to the literature devoted to the structural estimation of equilibrium search models of taste-based discrimination, already presented in the Introduction. It would be interesting to develop and estimate a model featuring both types of discrimination. However, accounting for taste-based discrimination should not affect the result whereby anti-SD is necessary to fit the large job loss rate differential.

Human capital accumulation.-Our model neglects human capital accumulation as a potential factor of wage growth. Efficient wages partly account for experience because the log hourly wage of newly hired whites is regressed on age and age squared. However, this procedure implies that workers accumulate human capital during nonemployment episodes. Since blacks spend less time in employment, the computation magnifies the contribution of experience to black wages. Therefore efficient wages tend to overestimate wage gaps and the magnitude of this bias increases with age. Quantile differentials are likely to be smaller and increase less with quantiles than the ones we try to fit. Accounting for such a bias may improve the relevance of SD as a potential explanation of residual wage disparities. Estimating the effects of experience in structural search models is a non-trivial 
task (see Bagger et al. (2014)). The problem is a difficult one in our case where learning offers a competitive explanation for wage growth within firms. Therefore we mention it as a limit of our work and call for additional research.

On-the job search.-Job-shopping provides another engine of wage growth that we neglect. Workers may find a better job and obtain a pay rise by changing firms. Nothing prevents us from introducing on-the-job search in our model. However, it is unlikely to affect our main result that learning is faster with black workers. Moscarini (2005) extends his model to on-the-job search. Workers who contact an alternative employer benefit from a new start with fixed prior belief $p_{0}$. In our model, such workers would draw a new belief according to their group-specific prior distribution. As NS implies that whites draw better beliefs than blacks, the consideration of on-the-job search would naturally lead to the conclusion that white wages grow faster. The estimation would even be more in favor of anti-SD because on-the-job search alone would help to fit wage disparities. Of course, this argument is subject to the actual way to account for on-the-job search in the estimation. Here again, we call for additional research on the topic.

\section{Conclusion}

In the US, black workers spend more time in unemployment, lose their jobs more rapidly, and earn lower wages than white workers. This paper quantifies the contributions of statistical discrimination, as portrayed by negative stereotyping and screening discrimination, to such employment and wage disparities. We develop an equilibrium search model of statistical discrimination with learning based on Moscarini (2005) and estimate it by indirect inference. We show that statistical discrimination alone cannot simultaneously explain the observed differences in residual wages and monthly job loss probabilities between black and white workers. However, a model with negative stereotyping, larger unemployment valuation and faster learning about the quality of matches for black workers can account for these facts. One implication of our findings is that black workers have larger returns to tenure.

There are several avenues for research. First, the model and estimation methodologies can be applied to alternative datasets and groups of workers. Second, it would be worth providing microfoundations to exogenous key parameters like the ethnic-specific degree of observability of true match quality (see, e.g., Cavounidis and Lang (2015) who argue that managers have more incentive to monitor blacks 
because these workers historically had lower skills). A third set of extensions would enrich the current model. For instance, we could introduce on-the-job search and human capital investment to improve our knowledge of returns to tenure and experience for blacks and whites. 


\section{References}

Aigner, D. J. AND G. G. CAIN, "Statistical theories of discrimination in labor markets," Industrial and Labor Relations Review 30 (1977), 175-187.

Arrow, K. J., "The Theory of Discrimination," in O. Ashenfelter and A. Rees, eds., Discrimination in Labor Markets (Princeton: Princeton University Press, 1973).

Bagger, J., F. Fontaine, F. Postel-Vinay and J.-M. Robin, “Tenure, experience, human capital, and wages: A tractable equilibrium search model of wage dynamics," The American Economic Review 104 (2014), 1551-1596.

Becker, G. S., "The Economics of Discrimination," University of Chicago Press Economics Books (1971).

BLACK, D., "Discrimination in an Equilibrium Search Model," Journal of Labor Economics 13 (1995), 309-334.

BorowczyK-Martins, D., J. Bradley and L. TARAsonis, "Racial Discrimination in the U.S. Labor Market: Employment and Wage Differentials by Skill," IZA Discussion Papers 8176, Institute for the Study of Labor (IZA), May 2014.

Bowlus, A. J. AND Z. EcKsteIn, "Discrimination and Skill Differences in an Equilibrium Search Model," International Economic Review 43 (2002), 1309-1345.

Cavounidis, C. And K. LANG, “Discrimination and Worker Evaluation,” Technical Report, National Bureau of Economic Research, 2015.

Cornell, B. ANd I. Welch, "Culture, Information, and Screening Discrimination," Journal of Political Economy 104 (1996), 542-71.

DellaVigna, S. And M. D. Paserman, "Job Search and Impatience," Journal of Labor Economics 23 (2005), 527-588.

EcKsteIN, Z. AND K. I. WolpIN, "Estimating the effect of racial discrimination on first job wage offers," Review of Economics and Statistics 81 (1999), 384-392.

Elsby, M. W., B. Hobijn And A. SAHin, "The labor market in the Great Recession," Technical Report, National Bureau of Economic Research, 2010.

Flabbi, L., “Gender Discrimination Estimation in a Search Model with Matching and Bargaining," International Economic Review 51 (2010a), 745-783. 
- "Prejudice and gender differentials in the US labor market in the last twenty years," Journal of Econometrics 156 (2010b), 190-200.

Fryer JR, R. G., D. Pager and J. L. Spenkuch, "Racial Disparities in Job Finding and Offered Wages," Journal of Law and Economics 56 (2013), 633-689.

Gayle, G.-L. And L. Golan, “Estimating a Dynamic Adverse-Selection Model: Labour-Force Experience and the Changing Gender Earnings Gap 1968-1997," Review of Economic Studies 79 (2012), 227-267.

Gourieroux, C., A. Monfort and E. Renault, "Indirect inference," Journal of Applied Econometrics 8 (1993), S85-S118.

Holden, S. AND Å. Rosén, “Discrimination and employment protection," Journal of the European Economic Association 12 (2014), 1676-1699.

Jovanovic, B., "Matching, Turnover, and Unemployment," Journal of Political Economy 92 (1984), 108-22.

LANG, K., “A Language Theory of Discrimination," Quarterly Journal of Economics 101 (1986), 363-382.

LANG, K. AND J.-Y. K. LehmanN, “Racial Discrimination in the Labor Market: Theory and Empirics," Journal of Economic Literature 50 (2012), 959-1006.

Mailath, G. J., L. Samuelson and A. ShaKed, “Endogenous inequality in integrated labor markets with two-sided search," American Economic Review 90 (2000), 46-72.

Moro, A., “The Effect Of Statistical Discrimination On Black-White Wage Inequality: Estimating A Model With Multiple Equilibria," International Economic Review 44 (2003), 467-500.

Mortensen, D. T. and C. A. Pissarides, “Job Creation and Job Destruction in the Theory of Unemployment," Review of Economic Studies 61 (1994), 397-415.

Moscarini, G., "Job matching and the wage distribution," Econometrica 73 (2005), $481-516$.

Papageorgiou, T., "Learning Your Comparative Advantages," Review of Economic Studies 81 (2014), 1263-1295. 
Phelps, E. S., "The Statistical Theory of Racism and Sexism," American Economic Review 62 (1972), 659-61.

Ritter, J. A. And L. J. TAYlor, "Racial disparity in unemployment," Review of Economics and Statistics 93 (2011), 30-42.

RoséN, Å., “An equilibrium search-matching model of discrimination," European Economic Review 41 (1997), 1589-1613.

SHImer, R., "Reassessing the ins and outs of unemployment," Review of Economic Dynamics 15 (2012), 127-148.

Wonham, W. M., "Some applications of stochastic differential equations to optimal nonlinear filtering," Journal of the Society for Industrial \& Applied Mathematics, Series A: Control 2 (1964), 347-369. 


\section{A Measuring the ins and outs of unemployment}

To measure the monthly probability that an employed worker becomes unemployed, $J L P_{t}$, and the monthly probability that an unemployed worker finds a job, $J F P_{t}$, we follow Shimer (2012). Let $u_{t}$ denote the number of unemployed workers at the end of month $t$ and $u_{t}^{s}$ the number of workers who at time $t$ have been unemployed for less than a month; then $J F P_{t}$ can be backed out from the data using:

$$
u_{t+1}=\left(1-J F P_{t}\right) u_{t}+u_{t+1}^{s}
$$

which implies

$$
J F P_{t}=1-\frac{u_{t+1}-u_{t+1}^{s}}{u_{t}}
$$

To compute the job loss probabilities, we account for time aggregation bias and solve the following equation in $j l r_{t}$ :

$$
u_{t+1}=\frac{j f r_{t}}{j f r_{t}+j l r_{t}}\left(1-e^{-j f r_{t}-j l r_{t}}\right) l_{t}+e^{-j f r_{t}-j l r_{t}} u_{t},
$$

where $l_{t}$ is the labor force and $j f r_{t}=-\ln \left(1-J F P_{t}\right)$. Then, $j l r_{t}=-\ln \left(1-J L P_{t}\right)$.

\section{B Endogenous contact rate}

In the model the value of a vacancy is arbitrarily set to o, whereas the contact rate $\lambda$ is exogenous. As in Papageorgiou (2014), this assumption is innocuous. Suppose there is a constant-return to scale Cobb-Douglas matching function that sets the number of meets. Then the contact rate is $\lambda(x)=A x^{a}, 0<a<1$, where $x$ is the vacancy-to-unemployed ratio. Moreover, suppose that holding a vacancy involves paying the flow cost $\kappa$. The value of a vacancy $V$ solves

$$
r V=-\kappa+\frac{\lambda(x)}{x} \sum_{i} m_{i} \iint_{\underline{p}_{i}}^{1}\left[J_{i \alpha}(p)-V\right] d G_{i}^{0}(p) d \Psi_{i}(\alpha) .
$$

Assuming free entry of new firms leads to $V=0$ and so

$$
\kappa=\frac{\lambda(x)}{x} \sum_{i} m_{i} \iint_{\underline{p}_{i}}^{1} \alpha J_{i}(p) d G_{i}^{0}(p) d \Psi_{i}(\alpha) .
$$

Thus for a given set of parameter estimates and a given $\theta$, we compute the righthand side of equation (27) with $\lambda(x)=\lambda$, set $A=\lambda x^{-a}$ and $\kappa$ as the left-hand side of equation (27). 


\section{The solution of the HJB equation}

The solution is a slight amendment to Moscarini (2005). We first check that the proposed function solves equation (12) and then show that the optimal stopping belief is well-defined and belongs to the interval $(0,1)$. Hereafter we neglect type $\alpha$ and demographic group $i$. Let $n=\sqrt{1 / 4+2(r+\delta) / s^{2}}, s \equiv\left(\mu_{H}-\mu_{L}\right) / \sigma_{X}$. We obtain

$$
\begin{aligned}
& S^{\prime}(p)=c p^{-1 / 2-n}(1-p)^{-1 / 2+n}(1 / 2-n-p)+\frac{\mu_{H}-\mu_{L}}{r+\delta}, \\
& S^{\prime \prime}(p)=-c\left(1 / 4-n^{2}\right) p^{-3 / 2-n}(1-p)^{-3 / 2+n} .
\end{aligned}
$$

Plugging $S^{\prime}(p)$ and $S^{\prime \prime}(p)$ into (12) shows that (13) defines the solution.

Moreover, $c$ and $\underline{p}$ solve the following system of equations:

$$
\begin{aligned}
S^{\prime}(\underline{p}) & =c \underline{p}^{-1 / 2-n}(1-\underline{p})^{-1 / 2+n}(1 / 2-n-\underline{p})+\frac{\mu_{H}-\mu_{L}}{r+\delta}=0, \\
S(\underline{p}) & =c \underline{p}^{\frac{1}{2}-n}(1-\underline{p})^{\frac{1}{2}+n}+\frac{\bar{\mu}(\underline{p})-r U}{r+\delta}=0,
\end{aligned}
$$

The value of unemployment and the optimal stopping belief solve $r U=r U_{1}(p)=$ $r U_{2}(p)$, where

$$
\begin{aligned}
r U_{1}(x) & =\mu_{L}+x\left(\mu_{H}-\mu_{L}\right)+\left(\mu_{H}-\mu_{L}\right) \frac{x(1-x)}{n+x-1 / 2} \\
r U_{2}(x) & =\frac{b+\beta \lambda \int_{p \geq x}\left[c(x) p^{1 / 2-n}(1-p)^{1 / 2+n}+\frac{\bar{\mu}(p)}{r+\delta}\right] d G^{0}(p)}{1+\beta \lambda\left[1-G^{0}(x)\right] /(r+\delta)}, \\
c(x) & =\frac{\mu_{H}-\mu_{L}}{n+x-1 / 2} x^{1 / 2+n}(1-x)^{1 / 2-n} /(r+\delta) .
\end{aligned}
$$

Let $\phi(x)=r U_{1}(x)-r U_{2}(x)$. We have

$$
\begin{aligned}
& \phi(0)=\frac{\left(\mu_{L}-b\right)(r+\delta)-\beta \lambda\left(\mu_{H}-\mu_{L}\right) \int_{0}^{1} p d G^{0}(p)}{r+\delta+\beta \lambda}<0 \\
& \phi(1)=\mu_{H}-b>0
\end{aligned}
$$

by assumption (II). Therefore there is $\underline{p} \in(0,1)$ such that $\phi(\underline{p})=0$. Moreover,

$$
\begin{aligned}
r U_{1}^{\prime}(x)= & \frac{\left(\mu_{H}-\mu_{L}\right)\left(n^{2}-1 / 4\right)}{(n+x-1 / 2)^{2}}, \\
\left\{1+\beta \lambda\left[1-G^{0}(x)\right] /(r+\delta)\right\} r U_{2}^{\prime}(x)= & -\beta \lambda\left[c(x) x^{1 / 2-n}(1-x)^{1 / 2+n}+\frac{\bar{\mu}(x)}{r+\delta}-\frac{r U_{2}(x)}{r+\delta}\right] g^{0}(x) \\
& +\beta \lambda \int_{x} c^{\prime}(x) p^{1 / 2-n}(1-p)^{1 / 2+n} d G^{0}(p), \\
c^{\prime}(x)= & \frac{\left(\mu_{H}-\mu_{L}\right)\left(n^{2}-1 / 4\right)}{(n+x-1 / 2)^{2}} x^{-1 / 2+n}(1-x)^{-1 / 2-n} /(r+\delta) .
\end{aligned}
$$


In $x=p$, we have

$$
\begin{aligned}
\phi^{\prime}(\underline{p}) & =\frac{\left(\mu_{H}-\mu_{L}\right)\left(n^{2}-1 / 4\right)}{(n+\underline{p}-1 / 2)^{2}}-\frac{\beta \lambda}{1+\beta \lambda\left[1-G^{0}(\underline{p})\right] /(r+\delta)} \int_{\underline{p}} c^{\prime}(\underline{p}) p^{1 / 2-n}(1-p)^{1 / 2+n} d G^{0}(p) \\
& >\frac{\left(\mu_{H}-\mu_{L}\right)\left(n^{2}-1 / 4\right)}{(n+\underline{p}-1 / 2)^{2}}\left[1-\int_{p \geq \underline{p}}(p / \underline{p})^{1 / 2-n}((1-p) /(1-\underline{p}))^{1 / 2+n} d G^{0}(p)\right]>0
\end{aligned}
$$

because the term $p^{1 / 2-n}(1-p)^{1 / 2+n}$ decreases with $p$ on the interval $[0,1]$. It follows that $\underline{p}$ is uniquely defined by the requirement $\phi(\underline{p})=0$.

\section{Proofs}

Proof of Proposition I. ERgodic beLIEF Distribution

We neglect the index $i$. Let $y(p)=p^{2}(1-p)^{2} g(p)$. We have

$$
\left\{\begin{array}{l}
y^{\prime \prime}(p)+f(p)-\left(v^{2}-1 / 4\right) \frac{y(p)}{p^{2}(1-p)^{2}}=0, \\
\int_{p}^{1} g(p) d p=m-u \in[0, m] \\
y(\underline{p})=0
\end{array}\right.
$$

The general solution to problem $(*)$ has the form:

$$
\begin{aligned}
v y(p)= & {[p(1-p)]^{1 / 2-v} \times } \\
& \left\{c_{2} p^{2 v}+c_{1}(1-p)^{2 v}+p^{2 v} \int_{p}^{1} \frac{\lambda u g^{0}(x) x^{1 / 2-v}(1-x)^{1 / 2+v}}{2} d x\right. \\
& \left.-(1-p)^{2 v} \int_{p}^{1} \frac{\lambda u g^{0}(x) x^{1 / 2+v}(1-x)^{1 / 2-v}}{2} d x\right\},
\end{aligned}
$$

where $c_{1}$ and $c_{2}$ are two constant terms. According to the first boundary condition, $\int_{\underline{p}}^{1} g(p) d p$ converges, which implies that $c_{2}=0$. The second boundary condition gives $c_{1}=\lambda u k$. The unnormalized density results by dividing $y(p)$ by $p^{2}(1-$ $p)^{2}$. Three terms remain. The first term is always definite when $p<1$. The second term is finite for all $p<1$ when $g_{i}^{0}(1)$ is finite. As for the last term, the integral is finite under the assumption that there exist $A<\infty$ and $a>-1$ such that $\lim _{x \rightarrow 1} g_{i}^{0}(x)(1-x)^{1 / 2-v_{i}} /\left[A(1-x)^{a}\right]<1$.

\section{Proof of Proposition 2. Negative stereotyping}

Part A. Suppose $U_{W} \leq U_{B}$. Using (7) and (10), the value of unemployment can be rewritten as

$$
r U_{W}=b+\beta \lambda \int_{0}^{1} \max \left\{S_{W}(p), 0\right\} g_{W}^{0}(p) d p
$$


The surplus equation (12) implies that $S_{W}^{\prime \prime}(p)=S_{B}^{\prime \prime}(p)$ and thus $S_{W}(p) \geq S_{B}(p)$, for all $p \in[0,1]$. Using this fact

$$
r U_{W} \geq b+\beta \lambda \int_{0}^{1} \max \left\{S_{B}(p), 0\right\} g_{W}^{0}(p) d p .
$$

Since $S_{i}$ is strictly increasing in $p \in\left[p_{i^{\prime}} 1\right]$, Assumption 1 also implies

$$
b+\beta \lambda \int_{0}^{1} \max \left\{S_{B}(p), 0\right\} g_{W}^{0}(p) d p>b+\beta \lambda \int_{0}^{1} \max \left\{S_{B}(p), 0\right\} g_{B}^{0}(p) d p=r U_{B}
$$

And so we have proved $U_{W}>U_{B}$. This contradicts the assumption that $U_{W} \leq U_{B}$. Thus, $U_{W}>U_{B}$.

Part B. (i) Using equations (28) and (29), we obtain

$$
r U_{i}=\mu_{L}+\left(\mu_{H}-\mu_{L}\right)(n+1 / 2) \frac{\underline{p}_{i}}{n+\underline{p}_{i}-1 / 2} .
$$

The ratio is strictly increasing in $\underline{p}_{i}$. From part $\mathrm{A}$, we have $U_{W}>U_{B}$, which implies that $\underline{p}_{W}>\underline{p}_{B}$.

(ii) The group- $i$ specific job-finding rate is $j f r_{i}=\lambda\left[1-G_{i}^{0}\left(\underline{p}_{i}\right)\right], i=B, W$. The result follows from part (i) and Assumption 1.

(iii). At any time, the flow number of group- $i$ workers who lose their job is $\delta\left(1-u_{i}\right)+0.5 \sigma^{2}\left(\underline{p}_{i}\right) g_{i}^{\prime}\left(\underline{p}_{i}\right)$. Thus the group- $i$ specific job-loss rate is $j l r_{i}=\delta+$ $0.5 \sigma^{2}\left(\underline{p}_{i}\right) g_{i}^{\prime}\left(\underline{p}_{i}\right) /\left(1-u_{i}\right), i=B, W$. The result follows.

Part C. (i) We have $\omega_{i}(p)=\beta \bar{\mu}(p)+(1-\beta) r U_{i}$ for $i=B, W$ and $p \in\left[\underline{p}_{i^{\prime}} 1\right]$. This proves the result.

(ii) We have $\omega_{i q}=\beta\left(\mu_{H}-\mu_{L}\right) \tilde{G}_{i}^{-1}(q)+(1-\beta) r U_{i}+\beta \mu_{L}$. Therefore $z(0)=$ $\beta\left(\mu_{H}-\mu_{L}\right)\left(\underline{p}_{W}-\underline{p}_{B}\right)+(1-\beta) r\left(U_{W}-U_{B}\right)>z(1)=(1-\beta) r\left(U_{W}-U_{B}\right)$ by parts $\mathrm{A}$ and $\mathrm{B}(\mathrm{i})$.

\section{Proof of Proposition 3. Screening discrimination}

Part A. Let $U \equiv U\left(\sigma_{X}\right)$ denote the value of unemployment when the standard deviation of output is $\sigma_{X}$. By construction, we have $U_{B}=U\left(\sigma_{B}\right)$ and $U_{W}=U\left(\sigma_{W}\right)$. Using the notations of Appendix $C$, we have $r U\left(\sigma_{X}\right)=r U_{1}\left(\underline{p}, \sigma_{X}\right)=r U_{2}\left(\underline{p}, \sigma_{X}\right)$, where the dependence vis-à-vis $\sigma_{X}$ has been highlighted. Similarly we define $c\left(x, \sigma_{X}\right) \equiv c(x)$. 
We now show that $r U^{\prime}\left(\sigma_{X}\right)<0$. Let $f(x, n)=\frac{1}{n+x-1 / 2}\left[\frac{x /(1-x)}{p /(1-p)}\right]^{n}$. We have

$$
\begin{aligned}
\frac{\partial\left(r U_{1}\right)}{\partial \sigma_{X}} & =-\left(\mu_{H}-\mu_{L}\right) \frac{x(1-x)}{(n+x-1 / 2)^{2}} \frac{d n}{d \sigma_{X}}<0, \\
\frac{\partial\left(r U_{2}\right)}{\partial \sigma_{X}} & =\frac{\beta \lambda \int_{x} \frac{\partial}{\partial n}\left(c(x, n) p^{1 / 2-n}(1-p)^{1 / 2+n}\right) d G^{0}(p)}{1+\frac{\beta \lambda}{r+\delta}\left[1-G^{0}(x)\right]} \frac{d n}{d \sigma_{X}} .
\end{aligned}
$$

But $\frac{\partial}{\partial n}\left(c(x, n) p^{1 / 2-n}(1-p)^{1 / 2+n}\right)$ has the sign of $f_{n}(x, n)=\ln \left[\frac{x /(1-x)}{p /(1-p)}\right] f(x, n)-$ $\frac{f(x, n)}{n+x-1 / 2}<0$. Therefore $\frac{\partial\left(r U_{1}\right)}{\partial \sigma_{X}}<0$ and $\frac{\partial\left(r U_{2}\right)}{\partial \sigma_{X}}<0$ for all $x \in(0,1)$. It follows that $r U^{\prime}\left(\sigma_{X}\right)<0$ and so $U\left(\sigma_{X_{W}}\right)>U\left(\sigma_{X_{B}}\right)$.

Part B. (i) Let $\phi\left(x, \sigma_{X}\right)=r U_{1}\left(x, \sigma_{X}\right)-r U_{2}\left(x, \sigma_{X}\right)$. We have $d \underline{p} / d \sigma_{X}=-\frac{\phi_{\sigma_{X}}\left(p_{,}, \sigma_{X}\right)}{\phi_{x}\left(\underline{p, \sigma_{X}}\right)}$, which has the sign of $-\phi_{\sigma_{X}}\left(\underline{p}, \sigma_{X}\right)$. As shown in the proof of Part A, we have

$$
\begin{aligned}
& \phi_{\sigma_{X}}\left(\underline{p}, \sigma_{X}\right)=-\frac{\left(\mu_{H}-\mu_{L}\right) \underline{p}(1-\underline{p})}{(n+\underline{p}-1 / 2)^{2}} \frac{d n}{d \sigma_{X}}+\frac{\beta \lambda\left[1-G^{0}(\underline{p})\right]}{r+\delta+\beta \lambda\left[1-G^{0}(\underline{p})\right]} \frac{d n}{d \sigma_{X}} \times \\
& \frac{\left(\mu_{H}-\mu_{L}\right) \underline{p}(1-\underline{p})}{n+\underline{p}-1 / 2} \int_{\underline{p}}^{1}\left[\frac{1}{n+\underline{p}-1 / 2}-\ln \frac{\underline{p} /(1-\underline{p})}{p /(1-p)}\right] p(1-p)\left(\frac{\underline{p} /(1-\underline{p})}{p /(1-p)}\right)^{n} \frac{d G^{0}(p)}{1-G^{0}(\underline{p})} \\
& =-\frac{\left(\mu_{H}-\mu_{L}\right) \underline{p}(1-\underline{p})}{(n+\underline{p}-1 / 2)^{2}} \frac{d n}{d \sigma_{X}} \times\left\{1-\frac{\beta \lambda\left[1-G^{0}(\underline{p})\right]}{r+\delta+\beta \lambda\left[1-G^{0}(\underline{p})\right]} \times\right. \\
& \left.\int_{\underline{p}}^{1}\left[1-(n+\underline{p}-1 / 2) \ln \frac{\underline{p} /(1-\underline{p})}{p /(1-p)}\right]\left(\frac{\underline{p} /(1-\underline{p})}{p /(1-p)}\right)^{n} \frac{p(1-p) d G^{0}(p)}{1-G^{0}(\underline{p})}\right\} \\
& <-\frac{\left(\mu_{H}-\mu_{L}\right) \underline{p}(1-\underline{p})}{(n+\underline{p}-1 / 2)^{2}} \frac{d n}{d \sigma_{X}}\left\{1-\frac{1}{2} \int_{\underline{p}}^{1}\left[1-(n+\underline{p}-1 / 2) \ln \frac{\underline{p} /(1-\underline{p})}{p /(1-p)}\right]\left(\frac{\underline{p} /(1-\underline{p})}{p /(1-p)}\right)^{n} \frac{d G^{0}(p)}{1-G^{0}(\underline{p})}\right\} .
\end{aligned}
$$

which has the sign of $I=\frac{1}{2} \int_{\underline{p}}\left[1-(n+\underline{p}-1 / 2) \ln \frac{\underline{p} /(1-\underline{p})}{p /(1-p)}\right]\left(\frac{\underline{p} /(1-\underline{p})}{p /(1-p)}\right)^{n} \frac{d G^{0}(p)}{1-G^{0}(\underline{p})}-$ 1. Let $f(y)=y^{n} \ln y$. The function $f$ is such that $f(0)=f(1)=0$ and $f^{\prime}(y)=$ $y^{n-1}(1+n \ln y)$. Therefore $f(y) \geq-(n e)^{-1}$ for all $y \in[0,1]$. It follows that $I<$ $\frac{1}{2}+\frac{n+\underline{p}-1 / 2}{n e}-1<1 / e-1 / 2<0$. Thus $d \underline{p} / d \sigma_{X}>0$ and $\underline{p}_{B}>\underline{p}_{W}$.

(ii). The group- $i$ specific job-finding rate is $j f r_{i}=\lambda\left[1-G^{0}\left(\underline{p}_{i}\right)\right], i=B, W$. The result follows from part (i).

(iii). See the proof of Part B (iii) of Proposition 2.

Part C. (i) The result follows from Part A.

(ii). We have $z(0)=\beta\left(\mu_{H}-\mu_{L}\right)\left[\underline{p}_{W}-\underline{p}_{B}\right]+(1-\beta) r\left(U_{W}-U_{B}\right)<(1-$ $\beta) r\left(U_{W}-U_{B}\right)=z(1)$ by part B (i).

\section{Proof of Proposition 4. Unemployment valuation heterogeneity}


Part A. Let $U \equiv U(b)$ denote the value of unemployment when the utility flow derived from unemployment is $b$. By construction, we have $U_{B}=U\left(b_{B}\right)$ and $U_{W}=U\left(b_{W}\right)$. Using the notations of Appendix C, we have $r U(b)=r U_{1}(\underline{p})=$ $r U_{2}(p, b)$, where the dependence vis- $\tilde{A}$-vis $b$ has been highlighted. We have $\partial\left(r U_{2}(x, b)\right) / \partial b>0$ for all $x \in[0,1]$, which implies that $r U^{\prime}(b)>0$. Therefore $U\left(b_{B}\right)>U\left(b_{W}\right)$.

Part B. (i) Let $\phi(x, b)=r U_{1}(x)-r U_{2}(x, b)$. We have $d \underline{p} / d b=-\phi_{b}(\underline{p}, b) / \phi_{x}(\underline{p}, b)$, which has the sign of $-\phi_{b}(\underline{p}, b)$. But the proof of Part A shows that $\phi_{b}(\underline{p}, \bar{b})=$ $-\partial\left(r U_{2}(\underline{p}, b)\right) / \partial b<0$. Therefore $d \underline{p} / d b>0$ and $\underline{p}_{B}>\underline{p}_{W}$.

(ii). The group- $i$ specific job-finding rate is $j f r_{i}=\lambda\left[1-G^{0}\left(p_{i}\right)\right], i=B, W$. The result follows from part (i).

(iii). See the proof of part B (iii) of Proposition 2.

Part C. (i) The result follows from Part A.

(ii). We have $z(0)=\beta\left(\mu_{H}-\mu_{L}\right)\left[\underline{p}_{W}-\underline{p}_{B}\right]+(1-\beta) r\left(U_{W}-U_{B}\right)<(1-$ $\beta) r\left(U_{W}-U_{B}\right)=z(1)<0$ by parts $\mathrm{A}$ and $\mathrm{B}(\mathrm{i})$.

\section{E Algorithm to simulate individual histories}

To simulate individual labor market histories, we discretize time at monthly frequency and use the following steps to compute 500-month long histories for 25,000 individuals of each group.

1. All individuals start unemployed in the first period.

2. At the beginning of each period, unemployed find a job with probability $1-\exp \left(-\lambda\left[1-G_{i}^{0}\left(\underline{p}_{i}\right)\right]\right)$; the initial prior about match quality $p_{i 0}$ is drawn from the race-specific truncated distribution $G_{i}^{0}\left(p \mid p_{i 0}>\underline{p}_{i}\right)$. The true match quality is determined by an additional draw where the probability of being in a good-quality match is $p_{i 0}=\operatorname{Pr}\left(\mu=\mu_{H}\right)$.

3. At the beginning of each period, employed workers transit to unemployment with probability $1-\exp (-\delta)$.

4. Employed workers who are not hit by an exogenous shock in Step 3 remain active and flow output is $\mu+\sigma_{X i} Z_{1}$ where $Z_{1} \sim \mathcal{N}(0,1)$.

5. The probability that the match is good $p_{i t}$ is updated using equation (4). Workers in matches where $p_{i t}<\underline{p}_{i}$ become unemployed in the following period. 